\title{
Light-Induced Advanced Oxidation Processes as PFAS Remediation Methods: A Review
}

\author{
Domenico Leonello ${ }^{1}$, Murilo Alexandre Fendrich ${ }^{1}$ (D), Francesco Parrino ${ }^{2}$, Nainesh Patel ${ }^{3}$, Michele Orlandi ${ }^{1} \mathbb{D}$ \\ and Antonio Miotello $1, * \mathbb{D}$
}

1 Department of Physics, University of Trento, Via Sommarive 14, 38123 Trento, Italy; domenico.leonello@studenti.unitn.it (D.L.); murilo.fendrich@unitn.it (M.A.F.); michele.orlandi@unitn.it (M.O.)

2 Department of Industrial Engineering, University of Trento, Via Sommarive 9, 38123 Trento, Italy; francesco.parrino@unitn.it

3 Department of Physics and Electronics, Christ University, Bengaluru 560029, India; nainesh11@gmail.com

* Correspondence: antonio.miotello@unitn.it

check for updates

Citation: Leonello, D.; Fendrich, M.A.; Parrino, F.; Patel, N.; Orlandi, M.; Miotello, A. Light-Induced Advanced Oxidation Processes as PFAS Remediation Methods: A Review. Appl. Sci. 2021, 11, 8458. https://doi.org/10.3390/app11188458

Academic Editor: Roberto Zivieri

Received: 30 July 2021

Accepted: 9 September 2021

Published: 12 September 2021

Publisher's Note: MDPI stays neutral with regard to jurisdictional claims in published maps and institutional affiliations.

Copyright: (c) 2021 by the authors. Licensee MDPI, Basel, Switzerland. This article is an open access article distributed under the terms and conditions of the Creative Commons Attribution (CC BY) license (https:// creativecommons.org/licenses/by/ $4.0 /)$.

\begin{abstract}
PFAS substances, which have been under investigation in recent years, are certainly some of the most critical emerging contaminants. Their presence in drinking water, correlated with diseases, is consistently being confirmed by scientific studies in the academic and health sectors. With the aim of developing new technologies to mitigate the water contamination problem, research activity based on advanced oxidation processes for PFAS dealkylation and subsequent mineralization is active. While UV radiation could be directly employed for decontamination, there are nevertheless considerable problems regarding its use, even from a large-scale perspective. In contrast, the use of cheap, robust, and green photocatalytic materials active under near UV-visible radiation shows interesting prospects. In this paper we take stock of the health problems related to PFAS, and then provide an update on strategies based on the use of photocatalysts and the latest findings regarding reaction mechanisms. Finally, we detail some brief considerations in relation to the economic aspects of possible solutions.
\end{abstract}

Keywords: PFAS substances; emerging contaminants; water decontamination; photocatalysts; advanced oxidation processes

\section{Introduction}

Per- and poly-fluoroalkyl substances (PFASs) are highly fluorinated aliphatic compounds in which the hydrogen atoms are partially or totally replaced by fluorine atoms, resulting in the perfluoroalkyl moiety $\mathrm{C}_{n} \mathrm{~F}_{2 n+1}$ [1]. PFAS compounds are employed worldwide due to their outstanding chemical and physical properties: they are highly stable and show both hydrophobic and lipophobic functionalities. Applications include paintings, clothing, electrical conductors, Teflon ${ }^{\circledR}$ coatings and fluorotelomer production, firefighting foams, paper packaging products, and cookware. Among the most employed PFAS products are perfluorooctanoic (PFOA) and perfluorooctanesulfonic (PFOS) acid [2,3].

Nevertheless, PFASs are also reported to be persistent and bio-accumulative organic pollutants that are extremely toxic to living beings, with continuous exposure increasingly documented as the leading cause of adverse outcomes in humans such as immunotoxicity, hepatotoxicity, and carcinogenicity [4]. Moreover, these substances have been detected in a wide variety of samples including seawater, drinking water, ground water, indoor dust, plants, and the blood of humans and wildlife [5]. Due to the mounting evidence on dangerous effects and the still uncertain efficacy of treatment methods, PFASs are classified as contaminants of emerging concern (CEC), in addition to being considered as "forever chemicals". Once in the human blood, their elimination can require from months to years [6]. 
In recent years, different technologies have been developed aiming to purify water contaminated with PFAS compounds. Photolysis has been considered but given the C-F bond strength of around $480 \mathrm{~kJ} / \mathrm{mol}$ [7], impractical wavelengths shorter than $250 \mathrm{~nm}$ are needed to drive efficient cleavage.

Physical adsorption and redox process have been also investigated. Physical adsorption processes using powdered activated carbon (PAC) and granulated activated carbon (GAC) are the most studied and used techniques for PFAS removal from water. These techniques present the limitation of only transferring PFAS molecules from one medium to another, and therefore require further treatments downstream [5].

In this respect, redox processes present potential advantages towards PFAS degradation, enforcing continuous defluorination of the chain and thus featuring degradation to shorter and safer molecules and ultimately to mineralization $[1,3,8]$. Several efforts to develop cost-effective photocatalytic pathways are currently under investigation, although the overall photocatalytic defluorination and degradation mechanisms are quite complex and still need to be detailed. Novel photocatalytic materials in combination with various illumination sources have been tested for PFAS degradation, with relevant results. High degradation and defluorination efficiencies were achieved in neutral $\mathrm{pH}$ conditions, with photocatalyst materials (such as $\mathrm{In}_{2} \mathrm{O}_{3}$ nanoporous nanospheres $[9,10]$ and $\mathrm{Ga}_{2} \mathrm{O}_{3}$ needleand sheaf-like nanostructures [11]) which have drawbacks in terms of biocompatibility, availability, and cost. So far, the most likely solutions rely on the use of either $\mathrm{Fe}^{2+} / \mathrm{H}_{2} \mathrm{O}_{2}$ or $\mathrm{TiO}_{2} / \mathrm{O}_{3}$ combined with UV light under acidic $\mathrm{pH}$ [5].

The challenge here relies on the development of low-toxicity, efficient, and costeffective materials preferably featuring an optical energy gap compatible with the near UVvisible range (between 350 and $500 \mathrm{~nm}$ ), therefore providing the possibility of employing lower-cost radiation sources such as artificial visible light illumination, or concentrated sunlight, a clean and renewable resource.

In this review, an analysis of current literature on the applications of advanced oxidation processes for PFAS remediation in water is proposed, focusing on the materials and methods employed with an eye on economic viability. This report starts with a brief overview of PFAS applications and environmental and health concerns, as well as a comparison of conventional vs. emerging treatment methods and related analytical techniques. An extensive review is then presented on light-induced treatment methods (including photolysis), with an update on direct or sacrificial-mediated photocatalysis, materials, methods, and the corresponding reaction mechanisms. Finally, an overview of the employed radiation sources and an economic analysis provides a perspective on possible future outcomes for PFAS treatments as well as costs and efficiencies.

\section{PFAS Applications and Related Concerns}

\subsection{What Are PFASs Used for?}

PFASs can be divided into two main classes: polymers and non-polymers [12]. The most famous example of a non-polymer and one of the most employed PFASs is PFOA, used as a surfactant in the emulsion polymerization of fluoropolymers and as a building block for the synthesis of perfluoroalkyl-substituted compounds, polymers, and polymeric materials, with Teflon ${ }^{\circledR}$ being the most-well known example [13]. Fluorotelomer-based products (non-polymer PFASs) have been shown to degrade to PFOA over periods of decades, and thus they are a huge source of PFOA in the environment [14]. Generally, PFAS release at industrial facilities occurs through wastewater and stormwater discharge, on- and off-site disposal of solid waste, accidental releases through leaks and spills, and stack and fugitive emissions. Stack emissions may result in the aerial deposition of PFAS into soil and surface water (with subsequent leaching and infiltration to groundwater) related to the facility, as well as short- and long-range air transport of PFAS [3]. In a recent study, more than 200 applications in 64 categories identified nearly 1400 individual types of PFASs supplied by 21 industry branches. Among the use categories, medical instruments, the photographic industry, the semiconductor industry, coatings, paints and varnishes, 
fire-fighting foams, and printing are the largest employment categories, with more than 100 identified PFASs [15].

\subsection{Reasons for Concern}

So far, a substantial number of studies have proved many adverse effects of PFASs on human health. PFOS and PFOA, at concentrations of the order of few micrograms per liter in blood, may cause hypercholesterolemia, ulcerative colitis, thyroid disease, cancer, pregnancy-induced hypertension, pre-eclampsia, and liver damage. For each of these outcomes, a molecular mechanism has been tentatively proposed. In this regard, one of the most comprehensive collections of epidemiological studies linking adverse human health effects and many other problems to PFASs (particularly PFOA) is still under investigation and is authored by the $\mathrm{C} 8$ Science Panel $[4,16]$. Figure 1 summarizes the diseases already confirmed to be associated with PFAS substances.

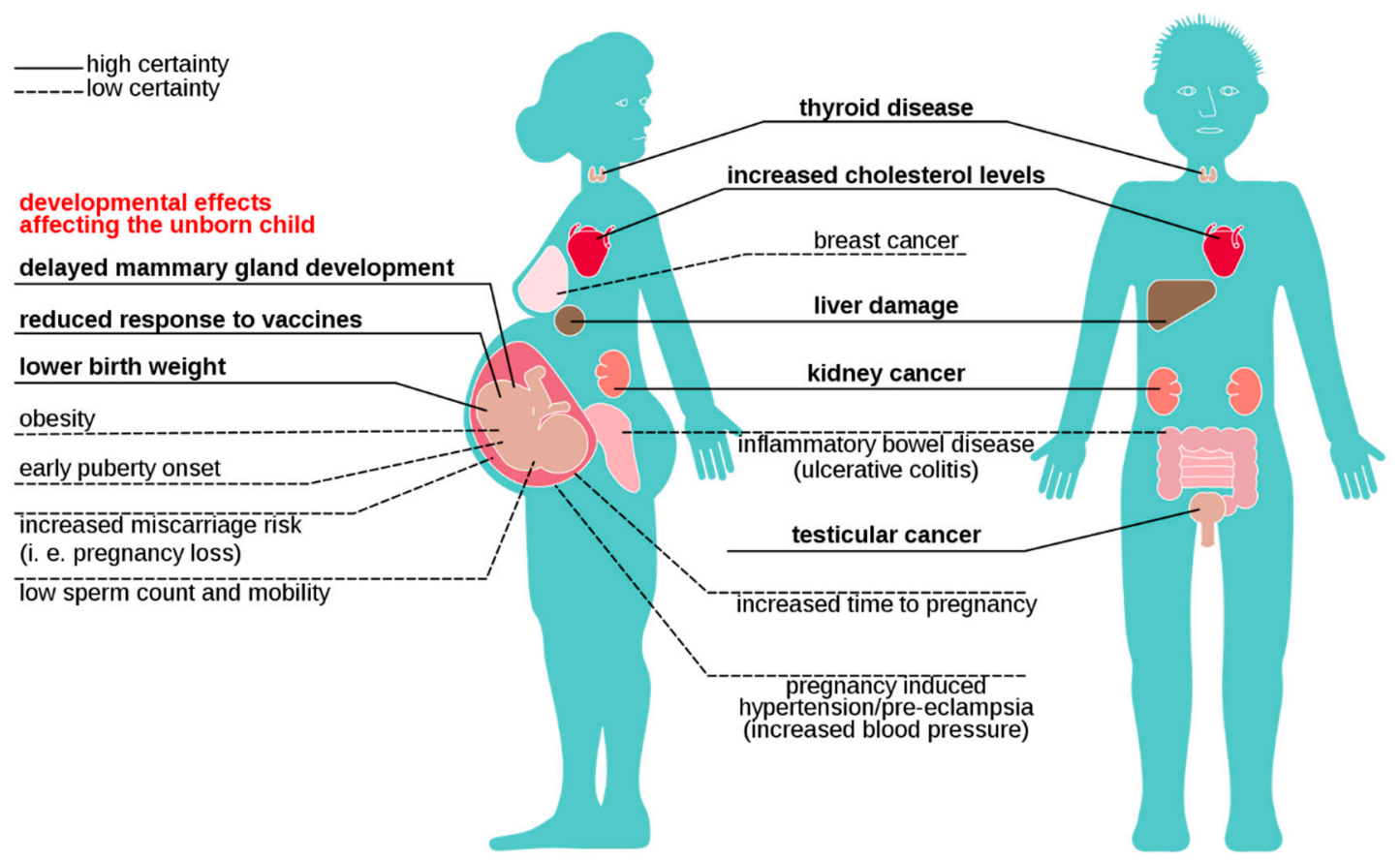

Figure 1. Effects of exposure to PFASs on human health. Some have confirmed certainty (continuous line), while others are still under study (dotted line) [17-22]. (From: https:/ / www.eea.europa.eu/publications/emerging-chemical-risks-ineurope/emerging-chemical-risks-in-europe (accessed on 31 March 2021)).

PFOA and PFOS are long-chain acids, meaning that the fluoroalkyl moiety $\left(-\mathrm{CF}_{2}-\right)_{n}$ with $n \geq 6$ presents a higher potential for adsorption than short-chain ones, leading to greater bioaccumulation and hence toxicity $[3,5]$. The serum half-life of perfluorobutanesulfonic acid (PFBS) $(n=4)$ was found to be approximately 44 days, whereas for PFOA it was reported to be 21 months, and for PFOS 35 months. Consequently, the persistence of such compounds leads to increased damage to human health [6]. Moreover, the half-lives of PFOS and PFOA has been compared with those of other substances under different follow-up times, and the results evidenced that the elimination levels for PFOA were slower after the range of 12 and 24 months, meaning that the average half-life can be as long as 48 months [6]. In addition, PFOA strongly bioaccumulates in the environment as compared to PFBS, with partition coefficient logarithms of 4.59 and 2.73, respectively [23]. Given the chemical structure of PFOA and PFBS, chains presenting the $\left(-\mathrm{CF}_{2}-\right)_{n}$ monomers with $n \leq 5$ are identified to be "safer" than longer chains. Further investigations are needed to better understand the behavior of short PFASs compounds and their effects on health.

A threshold of tolerable weekly intake (TWI) of 4.4 nanograms per kilogram of body weight per week is part of a scientific opinion on the risks to people's health deriving from 
the presence of these substances in food [24]. However, in contaminated drinking water, PFASs are sufficiently "abundant" that the TWI is easily overpassed just by drinking $2 \mathrm{~L}$ of water per day since the monitoring system of many PWSs (Public Water Systems) already report concentrations far above the actual limit of $0.5 \mu \mathrm{g} / \mathrm{L}$ of PFAS [3,25].

\subsection{Physical Separation vs. Advanced Oxidation Processes}

Physical separation methods remain the most common treatments for PFAS-contaminated liquids. Although such methods do not degrade PFAS, these processes are considered as a rapid solution involving only the mass transfer of PFAS from one media to another. These approaches can process extremely large volumes of liquid possessing low PFAS concentrations (levels of ppt to ppb), with the drawback of demanding consequent disposal, generally by incineration in furnaces [26].

Among physical separation technologies, the most employed techniques are procedures such as sorption on granulars of different particles, nanotubes of activated carbon (AC), biomaterials, molecularly imprinted polymers (resins), and mineral composites (e.g., zeolites). As mentioned, all these processes require further, generally off-site, treatment steps [27].

In the case of $A C$, the main issues are related to the poor removal of short-chained PFAS, difficulties in disposal, and eventually in the reactivation of carbon and the corresponding need for regeneration. These steps are necessary due to the reduction in removal efficiency with use. If frequent replacement of the material is ensured, AC can achieve $10-97 \%$ removal of PFAS [28].

The application of ion exchange resins provides up to $90-99 \%$ efficiency for some PFASs, although poor removal for selected PFAS is an unsolved problem, along with the potential complications related to the incineration and disposal of the adsorbents [29].

High-pressure filtration membranes are generally related to elevated capital and operation costs, uncertain corrosion control, lack of options for concentrate stream treatment or disposal, and finally membrane fouling. Furthermore, in this case, despite several disadvantages such as those mentioned above, the reported levels of PFAS removal from water range between $93 \%$ and $99 \%$ [30].

Emerging treatment methods are based on a series of chemical reactions which eventually result in PFAS degradation directly in water streams. Among these techniques, electrochemical oxidation, photocatalysis, photolysis, reduction processes using for example customized iodide or dithionite and sulfites, high-voltage electric discharges, bioremediation using microbial and fungal treatment, sonochemical degradation, ozonation under alkaline conditions, permanganate oxidation, sub or supercritical treatment, and microwave-hydrothermal treatments have been applied to PFAS degradation, with varying degrees of effectiveness [31]. Electrochemical oxidation, plasma, sonolysis, and hydrother$\mathrm{mal} /$ supercritical oxidation are some emerging technologies that are in the process of transitioning from laboratory-scale research to field-scale testing [32]. While promising, these technologies need extreme operating conditions, centralized laboratory equipment, and/or high chemical and energy requirements [30].

A combination of different approaches (perhaps using in situ and ex situ approaches) may be needed at a given site to cost-effectively address other areas with different water settings, orders of magnitude in concentration, co-contaminants, and remedial objectives. Selecting the most appropriate remedial strategy for PFAS is challenging. In this review paper we indicate the most promising technologies.

\subsection{Analytical Techniques for PFAS Detection in Water}

Qualitative and quantitative analysis of PFAS in water systems is extremely important, not only to assess the scale of contamination but also to inform and direct the development of remediation methods. Recent discussions [33] in the field of PFAS analysis highlighted the need to reach a consensus on standard methods for several analytes (short-chain 
PFAS in particular) and to validate methodologies beyond those for potable water. These objectives will require efforts regarding multi-laboratory validation for analytical methods.

Indeed, numerous analytical techniques for PFAS have been developed over time, in line with the observation of emerging contamination [33]. The most used methods in water systems to date are presented here.

\subsubsection{Chromatographic Techniques}

Several chromatography analysis techniques have been reported since the early 2000s, including gas chromatography (GC), high-performance liquid chromatography (HPLC), ultra-high-performance liquid chromatography (UHPLC), and capillary liquid chromatography (CLC). HPLC is in regular use for ionic PFASs such as perfluorinated carboxylic acids (PFCAs) and perfluorinated sulfonic acids (PFSAs), while GC is mostly employed for more volatile compounds such as fluorotelomer alcohols and perfluorinated sulfonamide ethanols [34]. Capillary electrophoresis has been investigated as an alternative for ionic and polar PFAS determination, but sensitivities and detection limits are lower than those of HPLC [31]. Specifically, the required detection limits for aqueous matrices can be in the range of parts-per-billion or even parts-per-trillion due to the health risks associated. For example, an analysis of groundwater contamination by recently identified PFAS compounds was conducted with a large-volume injection high-performance liquid chromatography (LVI-HPLC) procedure with a detection range of $0.71-67 \mathrm{ng} / \mathrm{L}$ (ppt) [35].

PFAS precursors varying in chain length (short or ultra-short chain) and moieties (anionic, cationic, or zwitterionic), have been detected in both tap and bottled water [36]. For ultra-short-chain PFAS, methods coupling LC to a quadrupole time-of-flight mass spectrometer (MS) as well as ultra-performance (UP) convergence chromatography coupled to MS were also reported [37,38]. The detection of 11 PFCAs and 4 PFSAs and short-chain PFCAs (C2-C8) at levels ranging from 70 to $200 \mathrm{ng} / \mathrm{L}$ in surface and ground waters was performed using HPLC-MS/MS [39,40], and an analysis of 19 PFAS in potable water was performed using UPLC-MS/MS [41].

HPLC coupled to ultra-high resolution orbitrap mass spectrometry (HPLC-uHRMS) for PFAS (C5-C17) monitoring showed to be advantageous in longer chain monitoring, with detection limits estimated at $0.005-0.2 \mathrm{ng} / \mathrm{mL}$ [42].

\subsubsection{Sensing Systems for PFAS Detection}

Since 2010, nanoscale materials have emerged as possible approaches for the monitoring of PFAS contaminants. Sensing nanomaterials present advantages due to the possibility of exploiting the unique physico-chemical properties of the nanometric size, such as aggregation, disaggregation, adsorption and desorption, potentially unparalleled sensitivity, and tunability. For example, chitosan-coated magnetite nanoparticles $\left(\mathrm{Fe}_{3} \mathrm{O}_{4}\right.$-C18-chitosanMNPs) were employed for the extraction of several PFAS compounds from both rainwater and tap water [43].

Gold nanoparticles (AuNP) are among the most studied nanosensors in general and for PFAS sensing. A significant improvement in this kind of sensing platform was obtained by employing peroxisome proliferator-activated receptor $\alpha$ (PPAR $\alpha$ )-responsive elements (PPRE) to modify AuNP sensors for the qualitative and quantitative analysis of PFAS in freshwater. This method was capable of detection at the ppt (2.5 ng/L) level [44]. Further efforts employing AuNPs were also reported using thiol-terminated-polystyrene, polyethylene glycol and perfluorinated thiols, polydopamine-polyvinylidene fluoro-membrane, and polydopamine [45-47].

The high sensitivity offered by surface-enhanced Raman scattering (SERS) was exploited to detect fluorosurfactants (FS) in groundwater using silver nanoparticles (AgNPs) for Raman enhancement. Immiscible ion pairs were formed between cationic dyes (methylene blue or ethyl violet) and anionic FSs. In addition, graphene oxide (GO) was used to enhance the loading of FSs [48]. 


\subsubsection{Total Fluorine Analysis (TF)}

Typical methods for organic and inorganic TF determination include particle-induced gamma-ray emission (PIGE), absorbable organic fluorine (AOF), and combustion ion chromatography (CIC). Recently, fluorine-19 nuclear magnetic resonance spectroscopy (19F-NMR), inductively coupled plasma-mass spectrometry (ICP-MS/MS), and X-ray photoelectron spectroscopy (XPS) were also reported on for fluorine detection [49-51].

\section{Advanced Oxidation Processes (AOPs) for PFAS}

\subsection{Heterogeneous Photocatalysis Materials}

Heterogeneous photocatalysis involving semiconductor catalysts provides one of the best remediation techniques for PFAS remediation by involving UV-Vis light and sometimes oxidation reactants [52-55]. The most important advantage of using photocatalysis is that both photo-oxidation and photoreduction pathways operate in tandem to effectively decompose PFAS to shorter-chain perfluoro carboxylic acid (PFCA) by the stepwise elimination of $\mathrm{CF}_{2}$ groups. Finally, these PFCA intermediates completely mineralize to $\mathrm{CO}_{2}$ and fluoride ions through repeating similar steps. The photocatalytic material, along with appropriate opto-electronic features, must also be chemically stable, recyclable, non-toxic, and available with a low price tag. Based on these requirements, Ti, Ga, In, and Bi-based compound photocatalysts have been primarily implemented in the literature to remove PFAS from wastewater (Table 1).

\subsubsection{Metal Oxides}

$\mathrm{TiO}_{2}$ was the first photocatalyst investigated for the removal of PFOA in water bodies [56] due to its well-known high activity towards the degradation of pollutants. However, $\mathrm{TiO}_{2}$ showed a very low reaction rate constant $\left(\sim 0.0001 \mathrm{~min}^{-1}\right)$, and high half-life ( $6931 \mathrm{~min})$ for PFOA degradation [57]. Similar problems were observed in the presence of titanate nanotubes (TNTs) synthesized by hydrothermal methods to improve the surface area, which were even less effective in removing PFAS under UV light [58]. This inefficiency of Ti-based photocatalysts was attributed to the strong repulsion of anionic PFAS molecules from the negatively charged surface of TNT. Commercial P25 TiO 2 , a benchmark in the field, was able to complete the degradation reaction of PFOA within $4 \mathrm{~h}$ under illumination with $254 \mathrm{~nm}$ UV light [59]. However, under higher wavelength light (315-400 nm), the degradation of PFOA decreased drastically. The photocatalytic ability of $\mathrm{TiO}_{2}$ to degrade organic pollutants mainly relies on the formation of $\mathrm{HO}^{\bullet}$ and $\mathrm{O}_{2}^{-} \bullet$ radicals by oxidation of water and reduction of $\mathrm{O}_{2}$ through photogenerated holes and electrons, respectively. Nevertheless, both these reactive oxidation species (ROS) are less active for the decomposition of PFOA. Thus, in the case of $\mathrm{TiO}_{2}$, photogenerated $\mathrm{h}^{+}$and $\mathrm{e}^{-}$directly initiate the decarboxylation of PFAS to mineralize them to $\mathrm{CO}_{2}$ and fluoride ions in a stepwise manner. For this phenomenon to occur, the absorption of PFAS molecule on $\mathrm{TiO}_{2}$ surface becomes a necessary condition. This can be achieved by spreading positive surface charges on the $\mathrm{TiO}_{2}$ by carrying out the photocatalytic reaction of PFAS in acidic conditions. Panchangan et al. [56] showed that in the presence of $0.15 \mathrm{M}$ perchloric acid, the rate constant of PFOA degradation increased by $\sim 46$ times with respect to that performed in the absence of acid. Following this work, most of the research for $\mathrm{TiO}_{2}$-based photocatalytic degradation of PFAS was performed at a $\mathrm{pH}$ below 4 . Acids such as oxalic acid increase the photoreduction capability of $\mathrm{TiO}_{2}$ to degrade PFAS. Wang et al. [60] demonstrated that adding oxalic acid leads to the formation of carboxyl anion radicals $\left(\mathrm{CO}_{2}^{-\bullet}\right)$ by photogenerated holes that have a higher reduction potential $(-1.85 \mathrm{~V})$ than that of photogenerated electrons. The same work also reported that oxalic acid is $~ 11.6$ times more effective in PFOA decomposition than perchloric acid under the equivalent $\mathrm{pH}$ of the reaction. $\mathrm{TiO}_{2}$ nanoparticles in the presence of oxalic acid effectively degrade $86.7 \%$ of PFOA in 180 min under $\mathrm{N}_{2}$ bubbling.

$\mathrm{TiO}_{2}$ supported on carbon allotropes such as MWCNT [61], graphene [62], and reduced-graphene oxide (rGO) [63] also increased the direct interaction between PFOA and $\mathrm{TiO}_{2}$ photocatalysis owing to the high adsorption capacity of the carbon-based material 
provided by the high surface area and surface functional group. Carbon can also trap the photogenerated electrons of $\mathrm{TiO}_{2}$ and reduce the electron-hole recombination process during the photocatalytic reaction. $\mathrm{TiO}_{2}-\mathrm{MWCNT}$ and $\mathrm{TiO}_{2}-\mathrm{rGO}$ were able to degrade $\sim 100 \%$ of PFOA under UV irradiation in $8 \mathrm{~h}$ and $12 \mathrm{~h}$, respectively. Recently, Shen et al. [64] fabricated $\mathrm{TiO}_{2}$ quantum dots of $2-5 \mathrm{~nm}$ in size on sulfonated graphene nanosheets using sodium dodecyl sulfate as a surfactant (Figure 2a). Due to the hydrophobic nature of sulfonate graphene and highly dispersed $\mathrm{TiO}_{2}$ quantum dots, PFOA pollutants could instantaneously be adsorbed on the surface, followed by fast decomposition by eliminating $\mathrm{CF}_{2}$ species. Apart from carbon, molecule-imprinted polymer (MIS)-modified $\mathrm{TiO}_{2}$ nanotubes also boosted contact between PFOA and $\mathrm{TiO}_{2}$ and reduced the recombination of $\mathrm{h}^{+}$ and $\mathrm{e}^{-}$pairs by capturing photogenerated electrons [65].

Noble metal nanoparticles deposited on $\mathrm{TiO}_{2}$ can also act as an electron sink to increase the lifetime of photogenerated $\mathrm{h}^{+}$and $\mathrm{e}^{-}$pairs. Among $\mathrm{Pt}, \mathrm{Pd}$, and $\mathrm{Ag}$ nanoparticles deposited by $\mathrm{TiO}_{2}, \mathrm{Pt}_{-} \mathrm{TiO}_{2}$ showed a considerable improvement ( 12.5 times) in the photocatalytic performance of PFOA removal as compared to pure $\mathrm{TiO}_{2}$ [66]. With the highest work function, $\mathrm{Pt}$ can attract more electrons from $\mathrm{TiO}_{2}$ to form a strong Schottky barrier at the interface, which improves $\mathrm{h}^{+} / \mathrm{e}^{-}$separation during irradiation. Weon et al. [67] successfully loaded $\mathrm{Pt}$ nanoparticles on the reductive sites of the $\mathrm{TiO}_{2}$ facet to precisely capture photoinduced electrons (Figure 2b). This charge separation led to an increase in the number of holes on $\mathrm{TiO}_{2}$ sites which participate in PFOA degradation. At the same time, electrons on the $\mathrm{Pt}$ atom produced hydrogen atoms and led to hydrogen spillover onto the $\mathrm{TiO}_{2}$ surface. The Ti-H bond formed on the surface facilitates hydrodefluorination of PFOA through the cleavage of the C-F bond. In addition to reducing recombination, doping with transition metals like $\mathrm{Cu}, \mathrm{Fe}$, and $\mathrm{Pb}$ also increased visible light absorption by lowering the band gap of $\mathrm{TiO}_{2}$, leading to superior photocatalytic degradation of PFAS [57,68]. Combining different strategies can lead to significant advancements in photocatalytic performance by creating a synergetic effect. Fe-deposited titanate nanotubes (TNT) supported on activated carbon (AC) (Fe/TNTs@AC) demonstrated highly efficient photodegradation of PFOA $(\sim 90 \%)$ in $4 \mathrm{~h}$ under UV light irradiation with $62 \%$ of the defluorination reaction [69]. In Fe/TNTs@AC, the nanotube architecture and AC provided a high surface area, while $\alpha-\mathrm{Fe}_{2} \mathrm{O}_{3}$ particles and AC considerably boosted PFOA adsorption on the surface and separation of the $\mathrm{h}^{+} / \mathrm{e}^{-}$pair by acting as the electron acceptor. Fe/TNTs@AC was recycled without significant loss in adsorption and degradation capacity of the photocatalyst. Similarly, Ga/TNTs@AC showed faster adsorption kinetics and degraded $~ 75.0 \%$ while mineralizing $66.2 \%$ of PFOS after $4 \mathrm{~h}$ of UV irradiation [70]. This type of study opens an avenue towards developing more such $\mathrm{TiO}_{2}$-based photocatalysts by integrating different strategies, with each modification step playing a specific role.

Along with $\mathrm{TiO}_{2}, \mathrm{ZnO}$ was also studied for remediating wastewater from PFAS but with limited success [71]. Although heterojunction between $\mathrm{ZnO} / \mathrm{rGO}$ did degrade $90.9 \%$ of PFOA [72], no other work on $\mathrm{ZnO}$ has been reported.

With a more negative conduction band edge and a wider band gap $(4.8 \mathrm{eV})$ than $\mathrm{TiO}_{2}$, gallium oxide $\left(\mathrm{Ga}_{2} \mathrm{O}_{3}\right)$ displayed a better capability for removing PFAS than $\mathrm{TiO}_{2}$. In contrast to $\mathrm{TiO}_{2}$, the scavenging experiment proved that the breaking down of PFOA proceeds via a reduction reaction in $\mathrm{Ga}_{2} \mathrm{O}_{3}$ involving photogenerated electrons to produce a rate constant $\sim 19$ times higher than that of $\mathrm{TiO}_{2}$ [73]. Nanostructured $\mathrm{Ga}_{2} \mathrm{O}_{3}$ in nanoneedle [74], sheaf-like [75], and nanorod [76] forms with improved surface area presented escalation in the demolition of PFOA from wastewater. Among them, the sheaf-like nanostructure assembled with nanoplates of an average width of $100 \mathrm{~nm}$ and thickness of $10 \mathrm{~nm}$ exhibited the highest reaction rate constant $\left(4.85 \mathrm{~h}^{-1}\right)$. Compared to commercial $\mathrm{Ga}_{2} \mathrm{O}_{3}$ and $\mathrm{TiO}_{2}$ powder, this value was $\sim 16$ and $\sim 44$ times higher, respectively. Nevertheless, the mechanism involved in all the nanostructures remained same where photoinduced electrons were used for the decarbonization of PFOA followed by HF elimination. To improve photocatalytic activity towards PFOA degradation, Huang and coworkers [77] modified $\mathrm{Ga}_{2} \mathrm{O}_{3}$ hierarchical nanosheets by doping a series of transition metals $(\mathrm{Mn}, \mathrm{Co}$, 
$\mathrm{Zn}, \mathrm{Cu}, \mathrm{Ti}$, and $\mathrm{In})$. Indium doping in the $\mathrm{Ga}_{2} \mathrm{O}_{3}$ hierarchical composite resulted best, completely degrading PFOA within $1 \mathrm{~h}$ with degradation kinetics $\sim 7.8$ times higher than those of pristine $\mathrm{Ga}_{2} \mathrm{O}_{3}$ (Figure 3a).

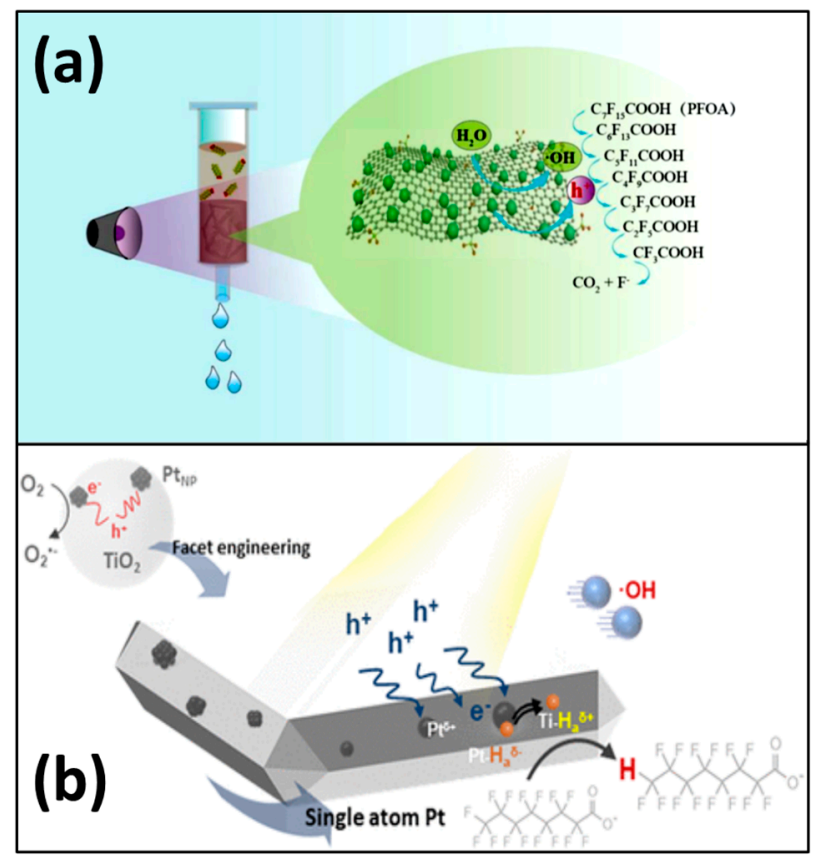

Figure 2. PFOA degradation using (a) $\mathrm{TiO}_{2}$ quantum dots supported on sulfonated graphene nanosheets (reprinted from [64], copyright (2020) with permission from Elsevier) and (b) single Pt atoms loaded on the reductive sites of the $\mathrm{TiO}_{2}$ facet (reprinted from [67], copyright (2021) with permission from ACS Publications).

By investigating the reaction mechanism, this considerable improvement was attributed to not only enhanced light absorption and charge separation but also to the activated surface that provided conducive conditions for better adsorption of PFOA.

$\mathrm{In}_{2} \mathrm{O}_{3}$ is highly active in removing PFAS, and it follows a similar photo-oxidation pathway as $\mathrm{TiO}_{2}$, but with significantly higher photocatalytic performance with a reaction rate approximately $\sim 59$ times higher than that of $\mathrm{TiO}_{2}$ [10]. As $\mathrm{In}_{2} \mathrm{O}_{3}$ provides the surface with better adsorption capacity for PFOA, photogenerated holes directly attack the carboxyl group of PFOA rather than forming the $\mathrm{HO}^{\bullet}$ radical as in $\mathrm{TiO}_{2}$. Since the surface plays the prime role in $\mathrm{In}_{2} \mathrm{O}_{3}$, substantial work on $\mathrm{In}_{2} \mathrm{O}_{3}$ was dedicated to refining the surface area by fabricating different nano morphologies like nanospheres, nanoplates, microspheres, and nanocubes $[9,78,79]$. Among them, nanoplates showed the highest surface area of $156.9 \mathrm{~m}^{2} / \mathrm{g}$, exposing many active sites and leading to the highest photocatalytic performance in the degradation of PFOA [79]. In recent work, $\mathrm{In}_{2} \mathrm{O}_{3}$ nanospheres derived from MOF offered a surface of a super-hydrophilic nature to facilitate the adsorption and tight attachment of PFOA [80]. This behavior results in complete decomposition and mineralization of PFOA in $3 \mathrm{~h}$ and $6 \mathrm{~h}$, respectively. Oxygen vacancies also play a vital role in these nanostructured $\operatorname{In}_{2} \mathrm{O}_{3}$ photocatalysts by acting as the adsorption sites for PFOA on the $\mathrm{In}_{2} \mathrm{O}_{3}$ surface. Higher photocatalytic activity has been recorded for nanostructures possessing greater amounts of oxygen vacancies. In addition to the adsorption of reactants, photogenerated charge separation is also essential for enhancing the photocatalytic reaction rate. As in other semiconductors, a strategy of heterojunction was also adopted for $\operatorname{In}_{2} \mathrm{O}_{3}$ to avoid the recombination process. Composites of $\operatorname{In}_{2} \mathrm{O}_{3}$ /graphene [81], $\mathrm{In}_{2} \mathrm{O}_{3} / \mathrm{Ce}_{2} \mathrm{O}_{3}$ (Figure 3b) [82], and $\operatorname{In}_{2} \mathrm{O}_{3} / \mathrm{MnO}_{x}$ (Figure 3c) [83], synthesized by cost-effective techniques, formed a heterojunction at the interface due to the difference in the energy levels, which drives the photogenerated $\mathrm{h}^{+}$and $\mathrm{e}^{-}$to spatially separated from each other. The synergic role played by both materials also escalated the adsorption of PFOA and the 
harvesting of visible light in the composite. All these promotive effects caused the complete decomposition of PFOA in $3 \mathrm{~h}$ for $\operatorname{In}_{2} \mathrm{O}_{3} /$ graphene and $\operatorname{In}_{2} \mathrm{O}_{3} / \mathrm{MnO}_{\mathrm{x}}$, and in $1 \mathrm{~h}$ for $\mathrm{In}_{2} \mathrm{O}_{3} / \mathrm{Ce}_{2} \mathrm{O}_{3}$ under UV light irradiation $(254 \mathrm{~nm})$, but with a higher intensity used in the case of $\mathrm{In}_{2} \mathrm{O}_{3} / \mathrm{Ce}_{2} \mathrm{O}_{3}$ composites. Oxy /hydroxide forms of In (InOOH) degrade PFOA, with a rate constant 27.6 times higher than that of the commercial P25 photocatalyst [84]. Enhanced adsorption of PFOA on the surface of $\mathrm{InOOH}$ is the prime factor responsible for higher photocatalyst performance compared to P25 under UV light irradiation.

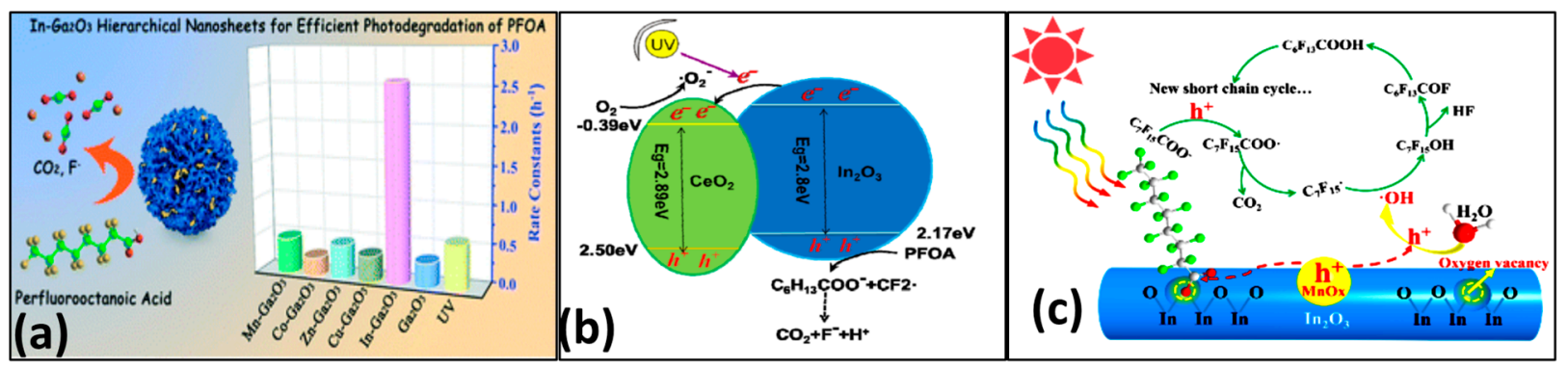

Figure 3. (a) Effect of transition metal doping in $\mathrm{Ga}_{2} \mathrm{O}_{3}$ hierarchical composites on PFOA degradation (reprinted from [77], copyright (2020) with permission from RSC Publishing). Photogenerated charge separation across the heterojunction of a (b) $\mathrm{In}_{2} \mathrm{O}_{3} / \mathrm{Ce}_{2} \mathrm{O}_{3}$ (reprinted from [82], copyright (2016) with permission from RSC Publishing) and (c) $\mathrm{In}_{2} \mathrm{O}_{3} / \mathrm{MnO}_{\mathrm{x}}$ composite (reprinted from [83], copyright (2019) with permission from John Wiley and Sons).

Mixed metal oxides possess multifunctionality qualities owing to the combined effect generated by different metals, where one metal will act as the active site, whereas the other metal modulates the electronic and structural configuration. Nadagauda and coworkers [85] synthesized the nanocrystalline ferrite catalyst $\mathrm{Zn}_{\mathrm{x}} \mathrm{Cu}_{1-\mathrm{x}} \mathrm{Fe}_{2} \mathrm{O}_{4}$ using a sol-gel autocombustion method for the degradation of PFOA in the presence of oxalic acid. Under UV light irradiation, $\mathrm{Zn}_{\mathrm{x}} \mathrm{Cu}_{1-\mathrm{x}} \mathrm{Fe}_{2} \mathrm{O}_{4}$ produces large quantities of ROS in aid of oxalic acid, as detected from intermediate products using liquid chromatography.

\subsubsection{Other Photocatalysts}

Bismuth oxyhalide (BiOX: where $\mathrm{X}=\mathrm{F}, \mathrm{CI}, \mathrm{Br}$, and I) photocatalysts are effective for the degradation of PFAS under light irradiation. Different bandgap and energy levels can be obtained for different $\mathrm{X}$ combinations, with $\mathrm{BiOF}, \mathrm{BiOCl}, \mathrm{BiOBr}$, and $\mathrm{BiOI}$ showing bandgaps of 3.99, 3.22, 2.64, and $1.77 \mathrm{eV}$, respectively [86]. The optical and electronic properties can be further tuned using two different combinations of $X$ in the compounds. Thus, these compounds provide the advantage of harvesting visible light for photocatalytic reactions. Most importantly, the formation energy for oxygen vacancies (OVs) of BiOX is very low, generating an abundant quantity of OVs on the surface. This feature further modulates the bandgap, providing sites for electron capture to delay the recombination of photogenerated charge carriers. The oxygen-deficient sites further participate in binding PFAS pollutants, with optimum interactions as compared to metal oxide. The layered structure of $\mathrm{BiOX}$ also offers a large surface-to-volume ratio with extensive exposure of active facets like (001). Because of these merits, BiOX showed an exceptional capability towards the photodegradation of PFOA, as reported first by Song et al. [87] for BiOCl. In their subsequent work [88], the same group systematically performed experiments to prove the linear relationship between the OVs and the photodegradation of PFOA. Doubling the OVs in BiOCl led to a four-fold increase in efficiency of defluorination in PFOA. The wide-bandgap BiOF photocatalyst can be modified by inducting OVs, which introduce the intermediate band in the forbidden gap to lower the energy required to excite the electrons by irradiation [89]. A study conducted by $\mathrm{Zu}$ and coworkers [89] demonstrated that OVs could be tuned on exposed (001) facets of BiOF by adjusting the concentration of ethylene glycol during synthesis. The BiOF (001) produced by using 50\% ethylene glycol could completely decompose PFOA within $6 \mathrm{~h}$ based on developed OVs. BiOI material, even 
with the smallest bandgap of $\sim 1.8 \mathrm{eV}$, was not conducive to the photocatalytic removal of PFAS, mainly owing to the lower valence band edge than that of the redox potential of $\left(\mathrm{HO}^{-} / \mathrm{HO}^{\bullet}\right)$ [90]. However, $\mathrm{BiOI}_{0.95} \mathrm{Br}_{0.05}$ displayed considerably high photocatalytic activity, requiring only $2 \mathrm{~h}$ to decompose $96 \%$ and $3 \mathrm{~h}$ to mineralize $65 \%$ of PFOA, thus showing the significance of the small amount of Br doping [90]. Here, rather than ROS, the holes and electrons played a more dominant role in the photocatalytic process. Doping of $\mathrm{Br}$ led to a reduction in bandgap for enhanced light harvesting and increased exposure of the (001) facet to elevate the separation of $\mathrm{h}^{+} / \mathrm{e}^{-}$pairs. This promoting characteristic of $\mathrm{BiOI}_{0.95} \mathrm{Br}_{0.05}$ produced a degradation rate constant $\sim 4.3$ times higher than that of BiOI. A similar boost in photocatalytic performance was observed when BiOI was mixed with $\mathrm{BiOF}$ and loaded with $\mathrm{Bi}$ nanoparticles to provide $\mathrm{Bi} / \mathrm{BiOI}_{1-\mathrm{x}} \mathrm{F}_{\mathrm{x}}$ [91]. Integrating both these bismuth oxyhalides further reduced the bandgap to increase the visible light absorption and elevated the surface area by two times due to the formation of hollow flower-like microspheres. On the other hand, Bi nanoparticles on the surface give rise to a surface plasma resonance effect to favor photogenerated charge separation by generating an electric field near the junction. Because of these properties, the $\mathrm{Bi} / \mathrm{BiOI}_{0.8} \mathrm{~F}_{0.2}$ composite presented the best activity for the decomposition of PFOA ( $40 \mathrm{mg} / \mathrm{L})$ in just $2 \mathrm{~h}$ of illumination of simulated solar light with a $~ 10$ times higher degradation rate than that of pure BiOF and $\mathrm{BiOI}$. As per the results of the EPR spectra and scavenging experiment, superoxide radicals $\left(\mathrm{O}_{2}^{-\bullet}\right)$ are dominant species for dissociating the bonds of PFOA. The $\mathrm{p}-\mathrm{n}$ heterojunction of $\mathrm{BiOI} @ \mathrm{Bi}_{5} \mathrm{O}_{7} \mathrm{I}$ (Figure 4a) was formed to improve charge separation by the facile heat treatment of $\mathrm{BiOI}$ in the air at a moderate temperature of $390{ }^{\circ} \mathrm{C}$ [92].

The resulting $\mathrm{p}-\mathrm{n}$ heterojunction causes photogenerated electrons to be immediately driven to the conduction band of $\mathrm{Bi}_{5} \mathrm{O}_{7} \mathrm{I}$ while leaving the holes in the valence band of $\mathrm{BiOI}$, thereby spatially separating $\mathrm{h}^{+} / \mathrm{e}^{-}$pair. This heterojunction is efficient in degrading $80 \%$ of PFOA in $6 \mathrm{~h}$ under irradiation with visible light, with the $\mathrm{HO}^{\bullet}$ radical as the oxidizing agent. Similar charge separation was observed in the case of the $\mathrm{Bi}_{5} \mathrm{O}_{7} \mathrm{I} / \mathrm{ZnO}$ n-n heterojunction microsphere, but here photogenerated holes were found to be responsible for attacking carboxylic groups of PFOA [93].

A novel $\mathrm{Bi}_{3} \mathrm{O}(\mathrm{OH})\left(\mathrm{PO}_{4}\right)_{2}(\mathrm{BOHP})$ compound, despite having a larger bandgap and lower surface area than $\mathrm{BiPO}_{4}$ and $\beta-\mathrm{Ga}_{2} \mathrm{O}_{3}$, showed $\sim 15$ times higher photocatalytic activity towards the degradation of PFOA [94]. The highly positive surface charge of $\mathrm{BOHP}$ induces an incremental rise in the adsorption behavior of PFOA on the surface. Along with this, the favorable redox potential of the BOHP also participates in enhancing PFOA mineralization. The performance of BOHP was amplified by $\mathrm{Xu}$ et al. [95], forming composites with carbon spheres (CS) and upgrading the stability of BOHP by suppressing the photo corrosion of the composites via acting as an electron sink. The adsorption capacity of PFOA was also improved through CS, which contributes to the adsorption of PFOA. Carbon spheres were also found to be beneficial for an iron (hydro)oxide photocatalyst (FeO), where a 1:1 composite of $\mathrm{FeO} / \mathrm{CS}$ was developed by the same research group that presented the BOHP/CS composites (Figure 4b) [96]. Here, CS aids in forming ferrihydride on the surface, which improves the adsorption of PFOA via binuclear and bidentate complexation and increases direct electron extraction from PFOA under stimulated solar light. FeO/CS was able to photodegrade $95.2 \%$ of PFOA, with $57.2 \%$ defluorination in $4 \mathrm{~h}$ in neutral $\mathrm{pH}$.

The wide-bandgap semiconductor boron nitride $(\mathrm{BN})$ was also reported for photocatalytic degradation of PFOA under UV light (Figure 5a) [97]. Boron nitride followed a similar photo-oxidation pathway as $\mathrm{TiO}_{2}$, mainly involving holes to bifurcate PFOA but with rate twice that of $\mathrm{TiO}_{2}$. The exfoliation of $\mathrm{BN}$ layers through ball milling further improved the degradation rate. Tungstic heteropoly acid $\left(\mathrm{H}_{3} \mathrm{PW}_{12} \mathrm{O}_{40}\right)$ supported on high-surface-area bimodal mesoporous silica (BMS) displayed an enhanced defluorination rate of PFOA compared to direct photolysis under vacuum UV light irradiation with a wavelength of $185 \mathrm{~nm}$ [98]. Recently, a Z-scheme-based heterojunction was discovered to be highly effective in photocatalytic applications, considering its ability to cause charge separation at 
the junction to increase the lifetime of photogenerated charges. Tang et al. [99] fabricated a Z-scheme heterojunction of core-shell $\mathrm{CeO}_{2} @ \mathrm{NiAl}-\mathrm{LDHs}$ (Figure $5 \mathrm{~b}$ ) to proficiently remove PFOA from wastewater. A built-in electric field in the Z-scheme heterojunction causes instantaneous separation of photogenerated charges to record photodegradation of $90.2 \%$ of PFOA under stimulated solar light. Although implementing various photocatalytic materials and their different forms and compounds provides the solution for adequate removal of PFAS, maintaining a conducive environment during the photocatalytic reaction is equally vital. Factors such as aerobic or anaerobic conditions, type of light used, $\mathrm{pH}$ and temperature of the solution, and the presence of other impurities are crucial in deciding the photocatalytic degradation rate of PFAS. The effect of these factors is covered in other review articles [100-103], and is out of scope for the present report.

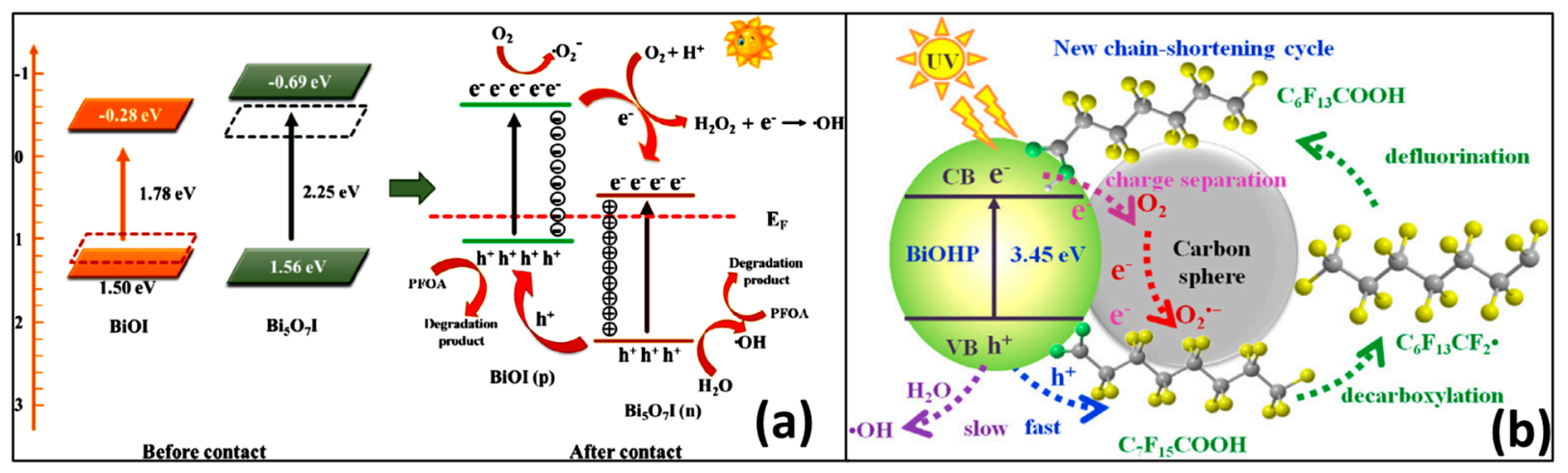

Figure 4. Charge separation and PFOA degradation (a) at the p-n heterojunction of $\mathrm{BiOI} @ \mathrm{Bi}_{5} \mathrm{O}_{7} \mathrm{I}$ (reprinted from [92], copyright (2020) with permission from Elsevier) and (b) in BOHP/CS composites (reprinted from [95], copyright (2020) with permission from Elsevier).
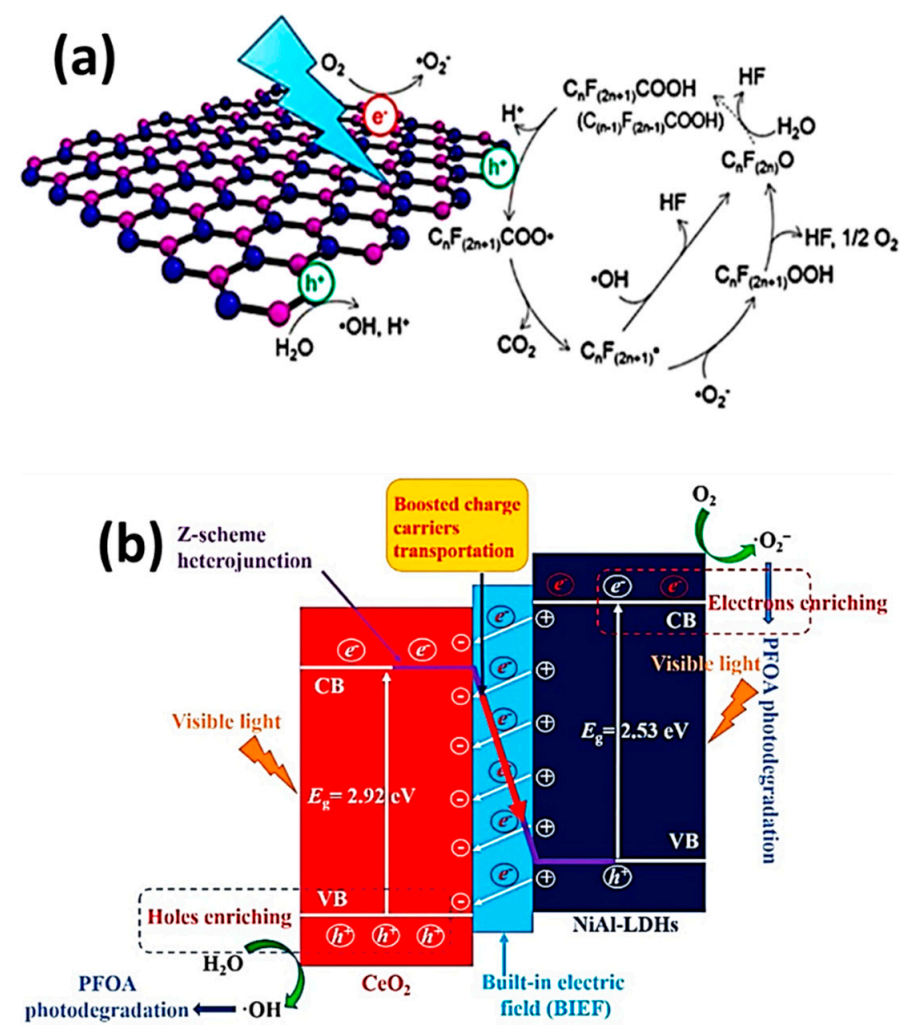

Figure 5. PFOA degradation mechanism over (a) boron nitride (reprinted from [97], copyright (2020) with permission from ACS publications) and (b) the z-scheme based heterojunction of core-shell $\mathrm{CeO}_{2} @ \mathrm{NiAl}-\mathrm{LDHs}$ (reprinted from [99], copyright (2021) with permission from Elsevier). 
Table 1. Heterogeneous photocatalysis applied to PFAS decontamination.

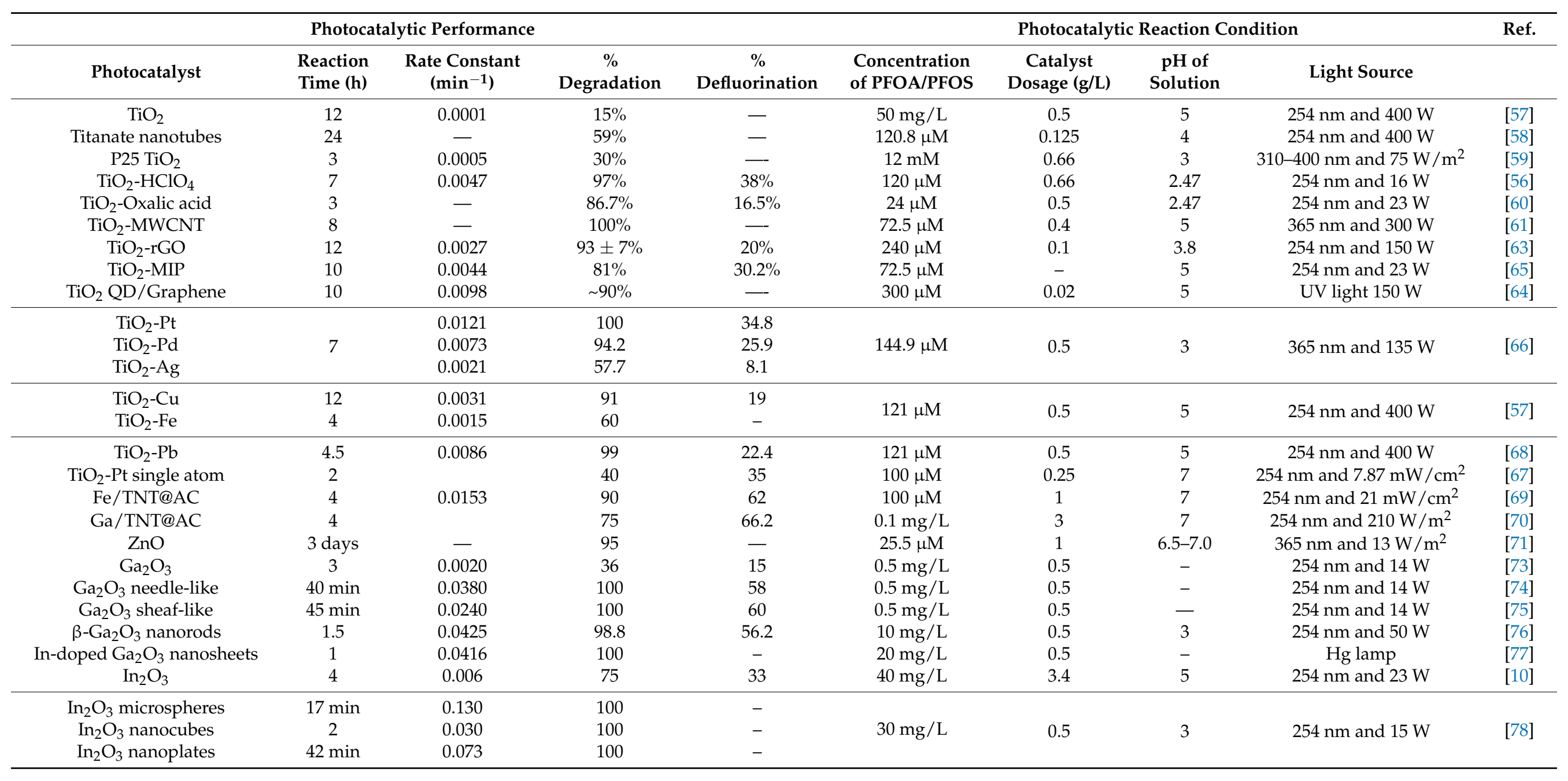


Table 1. Cont.

\begin{tabular}{|c|c|c|c|c|c|c|c|c|c|}
\hline \multicolumn{5}{|c|}{ Photocatalytic Performance } & \multicolumn{4}{|c|}{ Photocatalytic Reaction Condition } & \multirow[t]{2}{*}{ Ref } \\
\hline Photocatalyst & $\begin{array}{l}\text { Reaction } \\
\text { Time (h) }\end{array}$ & $\begin{array}{l}\text { Rate Constant } \\
\quad\left(\min ^{-1}\right)\end{array}$ & $\begin{array}{c}\% \\
\text { Degradation }\end{array}$ & $\begin{array}{c}\% \\
\text { Defluorination }\end{array}$ & $\begin{array}{l}\text { Concentration } \\
\text { of PFOA/PFOS }\end{array}$ & $\begin{array}{c}\text { Catalyst } \\
\text { Dosage (g/L) }\end{array}$ & $\begin{array}{c}\mathrm{pH} \text { of } \\
\text { Solution }\end{array}$ & Light Source & \\
\hline $\begin{array}{l}\mathrm{In}_{2} \mathrm{O}_{3} \text { nanoporous } \\
\text { nanospheres }\end{array}$ & $30 \mathrm{~min}$ & 0.100 & 100 & 71 & $30 \mathrm{mg} / \mathrm{L}$ & 0.5 & 3.9 & $254 \mathrm{~nm}$ and $23 \mathrm{~W}$ & {$[9]$} \\
\hline $\mathrm{In}_{2} \mathrm{O}_{3}$ porous nanoplates & $30 \mathrm{~min}$ & 0.158 & 100 & - & $30 \mathrm{mg} / \mathrm{L}$ & 0.5 & - & $254 \mathrm{~nm}$ and $15 \mathrm{~W}$ & [79] \\
\hline $\begin{array}{c}\text { MOF-derived } \operatorname{In}_{2} \mathrm{O}_{3} \\
\text { nanospheres }\end{array}$ & 3 & - & 100 & 50 & $10 \mathrm{mg} / \mathrm{L}$ & 0.2 & - & $254 \mathrm{~nm}$ and $32 \mathrm{~W}$ & [80] \\
\hline $\mathrm{In}_{2} \mathrm{O}_{3} /$ graphene & 3 & 0.008 & 100 & 60.9 & $30 \mathrm{mg} / \mathrm{L}$ & 0.5 & 3 & $254 \mathrm{~nm}$ and $15 \mathrm{~W}$ & [81] \\
\hline $\mathrm{In}_{2} \mathrm{O}_{3} / \mathrm{Ce}_{2} \mathrm{O}_{3}$ & 1 & 0.063 & 100 & 53.3 & $100 \mathrm{mg} / \mathrm{L}$ & 0.4 & - & $254 \mathrm{~nm}$ and $500 \mathrm{~W}$ & [82] \\
\hline $\mathrm{In}_{2} \mathrm{O}_{3} / \mathrm{MnOx}$ & 3 & 0.301 & 100 & 17.4 & $50 \mathrm{mg} / \mathrm{L}$ & 0.5 & 3.8 & Xenon lamp and $500 \mathrm{~W}$ & [83] \\
\hline $\mathrm{InOOH}$ & 3 & 0.008 & 83.4 & - & $20 \mathrm{mg} / \mathrm{L}$ & 0.25 & & $254 \mathrm{~nm}$ and $18 \mathrm{~W}$ & [84] \\
\hline $\mathrm{BiOCl}$ & 12 & - & 100 & 59.3 & $20 \mu \mathrm{M}$ & 0.5 & 4.8 & $254 \mathrm{~nm}$ and $10 \mathrm{~W}$ & [87] \\
\hline $\mathrm{BiOCl}$ with $\mathrm{OV}$ & 8.5 & - & 68.8 & 12.86 & $50 \mu \mathrm{M}$ & 1 & 2 & Xenon lamp and $300 \mathrm{~W}$ & [88] \\
\hline $\mathrm{BiOF}$ & 6 & 0.006 & 100 & 56.8 & $15 \mathrm{mg} / \mathrm{L}$ & & $3-5$ & UV light & [89] \\
\hline $\mathrm{BiOI}$ & 2 & 0.0048 & 66 & $37 \%$ in $3 h$ & $20 \mathrm{mg} / \mathrm{L}$ & 0.4 & - & $\mathrm{Hg}$ lamp and $300 \mathrm{~W}$ & [90] \\
\hline $\mathrm{BiOI}_{0.95} \mathrm{Br}_{0.05}$ & 2 & 0.0205 & 100 & $65 \%$ in $3 h$ & $20 \mathrm{mg} / \mathrm{L}$ & 0.4 & - & $\mathrm{Hg}$ lamp and $300 \mathrm{~W}$ & [90] \\
\hline $\mathrm{Bi} / \mathrm{BiOI}_{1}-\mathrm{xFx}$ & 2 & 0.0375 & 100 & 10 & $40 \mathrm{mg} / \mathrm{L}$ & 0.4 & $3-5$ & Xenon lamp and $800 \mathrm{~W}$ & [91] \\
\hline BOHP & 1 & 0.1000 & 100 & 60 & $0.13 \mathrm{mM}$ & 1.8 & 4 & $254 \mathrm{~nm}$ and $18 \mathrm{~W}$ & [94] \\
\hline $\mathrm{BOHP} / \mathrm{CS}$ & 4 & - & 100 & 32.5 & $0.2 \mathrm{mg} / \mathrm{L}$ & 1.0 & 7 & $254 \mathrm{~nm}$ and $18 \mathrm{~W}$ & [95] \\
\hline $\mathrm{FeO} / \mathrm{CS}$ & 1 & - & 95.2 & 57.2 & $0.2 \mathrm{mg} / \mathrm{L}$ & 1.0 & 7 & Stimulated solar light & [96] \\
\hline Boron nitride & 4 & & 100 & 52 & $0.12 \mathrm{mM}$ & 2.5 & 6.5 & $254 \mathrm{~nm}$ and $24 \mathrm{~W}$ & [97] \\
\hline $\begin{array}{c}\mathrm{H}_{3} \mathrm{PW}_{12} \mathrm{O}_{40} / \text { bimodal } \\
\text { mesoporous silica }\end{array}$ & 4 & 0.0018 & & 50 & $10 \mathrm{mg} / \mathrm{L}$ & 0.2 & 4 & $254 \mathrm{~nm}$ and $8 \mathrm{~W}$ & [98] \\
\hline
\end{tabular}




\subsubsection{Reaction Mechanisms}

The mineralization of PFOA in water can be summarized as in Equation (1)

$$
\mathrm{CF}_{3}\left(\mathrm{CF}_{2}\right)_{6} \mathrm{COOH}+7 / 2 \mathrm{O}_{2}+7 \mathrm{H}_{2} \mathrm{O} \rightarrow 8 \mathrm{CO}_{2}+15 \mathrm{HF}
$$

The reaction has been investigated in irradiated aqueous suspensions of $\mathrm{TiO}_{2}$, one of the most extensively investigated photocatalysts, and the commonly accepted mechanism is the result of a photo-redox and $\beta$-scission pathway [104]

Upon irradiation of suitable energy, electrons $\left(\mathrm{e}^{-} \mathrm{CB}\right)$ and holes $\left(\mathrm{h}^{+} \mathrm{VB}\right)$ are localized respectively within the conduction and valence band of $\mathrm{TiO}_{2}$ [105], according to Equation (2).

$$
\mathrm{TiO}_{2}+\mathrm{h} v \rightarrow \mathrm{TiO}_{2}\left(\mathrm{e}^{-}{ }_{\mathrm{CB}} ; \mathrm{h}^{+}{ }_{\mathrm{VB}}\right)
$$

It is worth noting that PFOA exists mainly in its deprotonated form under natural $\mathrm{pH}$ conditions. Deprotonated PFOA undergoes hole-induced Kolbe decarboxylation $[60,106,107]$, giving rise to the C7 radical intermediate (Equation (3)), which in turn reacts with molecular oxygen, producing a peroxy-radical [108] (Equation (4))

$$
\begin{gathered}
\mathrm{CF}_{3}\left(\mathrm{CF}_{2}\right)_{6} \mathrm{COO}^{-}+\mathrm{h}_{\mathrm{VB}}^{+} \rightarrow \mathrm{CF}_{3}\left(\mathrm{CF}_{2}\right)_{5} \mathrm{CF}_{2} \cdot+\mathrm{CO}_{2} \\
\mathrm{CF}_{3}\left(\mathrm{CF}_{2}\right)_{5} \mathrm{CF}_{2} \cdot+\mathrm{O}_{2} \rightarrow \mathrm{CF}_{3}\left(\mathrm{CF}_{2}\right)_{5} \mathrm{CF}_{2} \mathrm{OO}
\end{gathered}
$$

The coupling of two peroxyradicals forms molecular oxygen and two oxyradicals (Equation (5)).

$$
2 \mathrm{CF}_{3}\left(\mathrm{CF}_{2}\right)_{5} \mathrm{CF}_{2} \mathrm{OO} \cdot \rightarrow 2 \mathrm{CF}_{3}\left(\mathrm{CF}_{2}\right)_{5} \mathrm{CF}_{2} \mathrm{O} \cdot+\mathrm{O}_{2}
$$

The oxyradical undergoes electron-coupled hydrogen abstraction from water and evolves to an unstable primary perfluorinated alcohol [109] (Equation (6)), which eventually leads to acylfluoride and hydrogen fluoride [110] (Equation (7))

$$
\begin{gathered}
\mathrm{CF}_{3}\left(\mathrm{CF}_{2}\right)_{5} \mathrm{CF}_{2} \mathrm{O}+\mathrm{H}_{2} \mathrm{O}+\mathrm{e}^{-} \mathrm{CB} \rightarrow \mathrm{CF}_{3}\left(\mathrm{CF}_{2}\right)_{5} \mathrm{CF}_{2} \mathrm{OH}+\mathrm{OH}^{-} \\
\mathrm{CF}_{3}\left(\mathrm{CF}_{2}\right)_{5} \mathrm{CF}_{2} \mathrm{OH} \rightarrow \mathrm{CF}_{3}\left(\mathrm{CF}_{2}\right)_{5} \mathrm{C}(\mathrm{O}) \mathrm{F}+\mathrm{HF}
\end{gathered}
$$

Finally, the acyl fluoride undergoes hydrolysis to the C6 carboxylic acid (Equation (8))

$$
\mathrm{CF}_{3}\left(\mathrm{CF}_{2}\right)_{5} \mathrm{C}(\mathrm{O}) \mathrm{F}+\mathrm{H}_{2} \mathrm{O} \rightarrow \mathrm{CF}_{3}\left(\mathrm{CF}_{2}\right)_{5} \mathrm{COOH}+\mathrm{HF}
$$

This in turn can undergo the same photo-redox mechanism several times until the chain length is reduced step by step [111].

Another pathway relies on the capability of the oxyradical C7 generated in Equation (5) to undergo monomolecular $\beta$-scission by eliminating fluorofosgene $\left(\mathrm{COF}_{2}\right)$ and giving rise to a C6 perfluoroalkyl radical [112-114] (Equation (9)).

$$
\mathrm{CF}_{3}\left(\mathrm{CF}_{2}\right)_{5} \mathrm{CF}_{2} \mathrm{O} \cdot \rightarrow \mathrm{COF}_{2}+\mathrm{CF}_{3}\left(\mathrm{CF}_{2}\right)_{4} \mathrm{CF}_{2}
$$

Fluorofosgene is easily hydrolyzed to $\mathrm{HF}$ and $\mathrm{CO}_{2}$ (Equation (10))

$$
\mathrm{COF}_{2}+\mathrm{H}_{2} \mathrm{O} \rightarrow \mathrm{CO}_{2}+2 \mathrm{HF}
$$

The perfluoroalkyl radical can undergo the reaction steps as described above, starting from Equation (4). The mechanism described above is schematically represented in Figure 6. 


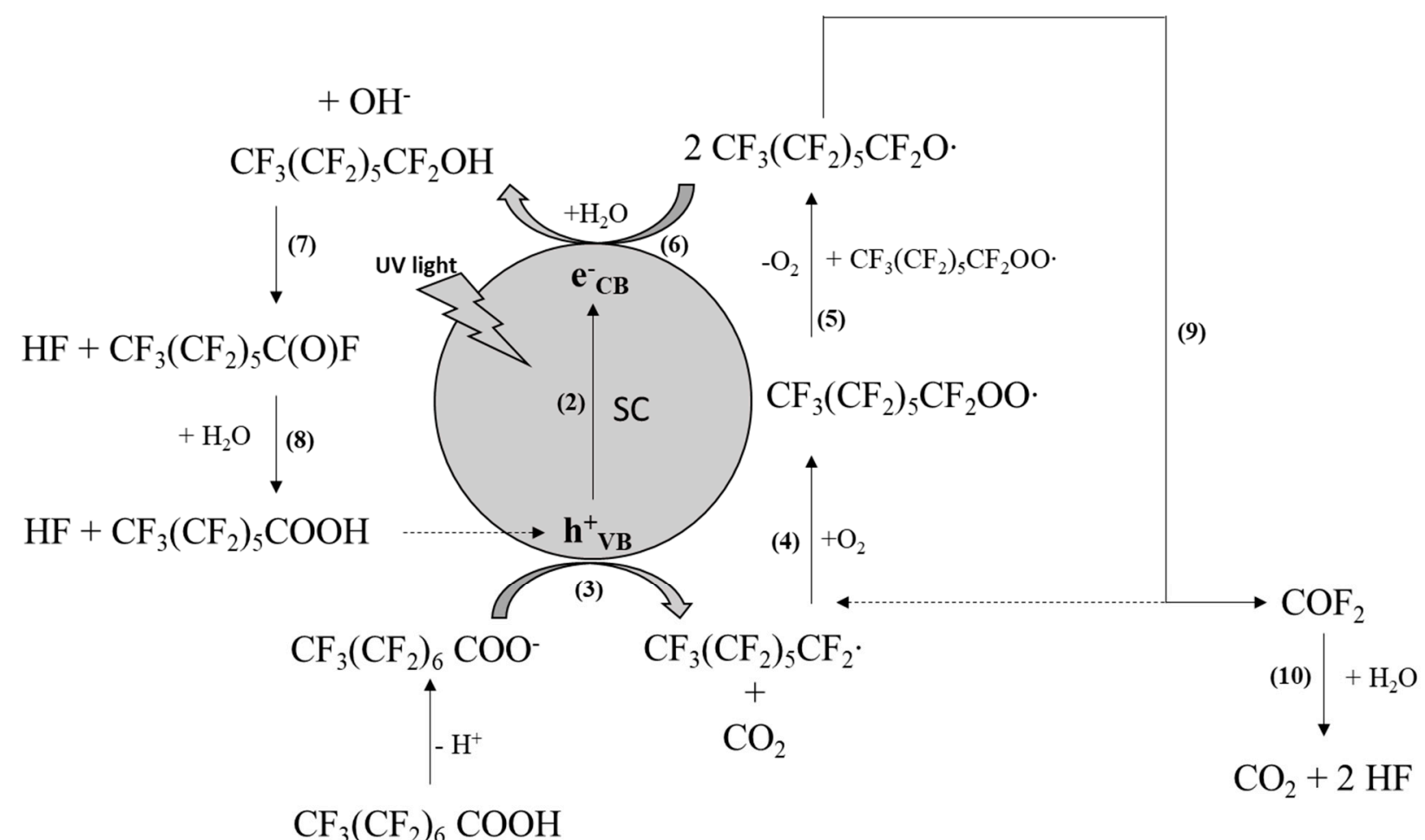

Figure 6. A hypothesized degradation mechanism of PFOA. Dashed lines indicate that the Cn product undergoes the same path, reducing the number of carbon atoms step by step.

Notably, the $\beta$-scission mechanism (Equations (9) and (10)) induces the decomposition of PFOA without forming carboxylic intermediates, which instead are produced when the photoredox mechanism (Equations (3)-(8)) occurs. Therefore, the concentration of shorter-chain perfluorinated acids should increase proportionally to fluoride formation if the photoredox mechanism preferentially occurs. Gatto et al. [104] observed that the shorter-chain carboxylic acids slowly started to form after switching on the lamp, but during the first hours of reaction, a direct correlation between PFOA mineralization and fluoride formation was evident. This suggests that the reaction takes place initially through the predominant $\beta$-scission mechanism, which efficiently competes with the photo-redox one. The authors also observed a slight loss of fluoride ions of ca. $3 \%$ in the aqueous phase, possibly due to fluorination of the surface of $\mathrm{TiO}_{2}$.

On the other hand, for longer reaction times the mineralization of PFOA nearly stopped, and an enhanced formation of shorter chain carboxylic acids was observed, with a concentration trend following the molecular weight of the intermediates. This indicates the preferential occurrence of the photo-redox mechanism with longer reaction times.

Another mechanism proposed in literature relies on the initial one-electron reduction of PFOA by photogenerated electrons, which results in the defluorination of the terminal perfluorinated carbon atom and the consequent formation of the corresponding perfluoroalkyl radical (Equation (11)). The latter in turn abstracts a hydrogen atom from the water, forming an $\mathrm{OH}$ radical and a monohydrogenated intermediate (Equation (12)). Repeating the same pathway results in the progressive hydrogenation of the alkyl chain, eventually leading to mineralization [54].

$$
\begin{gathered}
\mathrm{CF}_{3}\left(\mathrm{CF}_{2}\right)_{6} \mathrm{COOH}+\mathrm{e}^{-} \mathrm{CB} \rightarrow \mathrm{CF}_{2}\left(\mathrm{CF}_{2}\right)_{6} \mathrm{COOH}+\mathrm{F}^{-} \\
\mathrm{CF}_{2}\left(\mathrm{CF}_{2}\right)_{6} \mathrm{COOH}+\mathrm{H}_{2} \mathrm{O} \rightarrow \mathrm{HCF}_{2}\left(\mathrm{CF}_{2}\right)_{6} \mathrm{COOH}+\mathrm{OH}
\end{gathered}
$$

This pathway seems less probable compared to the other above-mentioned pathways considering the reduction of oxygen, which should preferentially occur. 
Finally, it is worth noting that direct photolysis of PFOA could take place only under irradiation shorter than $220 \mathrm{~nm}$, which corresponds to the bond dissociation energy of the C-F bond, i.e., ca. $544 \mathrm{~kJ} / \mathrm{mol}[102,115]$.

Only ca. $10 \%$ of degradation was observed through photolysis at $254 \mathrm{~nm}[116,117]$.

It is worth noting that PFOA is almost inert towards the $\mathrm{OH}$ radicals produced in the presence of irradiated $\mathrm{TiO}_{2}\left(\mathrm{k}_{\mathrm{OH}+\mathrm{PFOA}} \leq 10^{5} \mathrm{M}^{-1} \mathrm{~s}^{-1}\right)$ [118], due to the absence of hydrogen atoms prone to $\mathrm{OH}$ radical abstraction in the PFOA structure. Moreover, the initial decarboxylation (Equation (3)) is not likely to be induced by $\mathrm{OH}$ radical attack. In fact, the perfluorination of the alkyl chain reduces the electronic density of the carboxylic moiety, making the $\mathrm{OH}$ radical-mediated electron transfer unfavorable. Therefore, $\mathrm{TiO}_{2}$, generally very active for the degradation of a wide range of organic substrates, is rather poorly efficient in the degradation of PFOA. Its activity is slightly enhanced only under highly acidic $\mathrm{pH}$ conditions $\left(\mathrm{HClO}_{4}, \mathrm{pH}<2\right)[56,119]$ where the $\mathrm{pH}$-dependent potential of the photogenerated holes is higher. An analogous situation is observed for the $\mathrm{TiO}_{2}-$ induced degradation of trichloroacetate, which does not possess any hydrogen atoms [120]. Therefore, the lower the efficiency of hole-induced water oxidation to $\mathrm{OH}$ radicals, the better the efficacy obtained in terms of PFOA degradation. Accordingly, other semiconductors with a poor ability to produce $\mathrm{OH}$ radicals are instead more active in PFOA degradation. For instance, $\mathrm{Li}$ et al. [10] found that the apparent rate constant for the degradation of PFOA was 8.4 times higher in the presence of $\mathrm{In}_{2} \mathrm{O}_{3}$ than in the presence of $\mathrm{TiO}_{2}$. This result was justified by considering the peculiar adsorption mode of PFOA onto the $\operatorname{In}_{2} \mathrm{O}_{3}$ surface and the higher hole availability for PFOA oxidation with respect to $\mathrm{TiO}_{2}$, where water oxidation preferentially occurs. PFOA is bound to $\operatorname{In}_{2} \mathrm{O}_{3}$ in a bidentate or bridging configuration, resulting in a vertical and ordered arrangement of chains (Figure 7a). On the $\mathrm{TiO}_{2}$ surface, $\mathrm{PFOA}$ instead binds in a monodentate way (Figure $7 \mathrm{~b}$ ) which results in a tilted configuration of the chains.

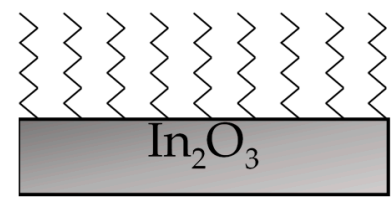

a)

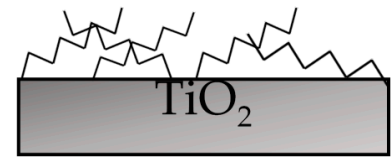

b)

\section{: Adsorbed PFOA molecules}

Figure 7. Adsorption modes of PFOA onto $\mathrm{In}_{2} \mathrm{O}_{3}(\mathbf{a})$ and $\mathrm{TiO}_{2}(\mathbf{b})$.

Consequently, some of the inner $\mathrm{CF}_{2}$ groups of PFOA can interact with the $\mathrm{TiO}_{2}$ surface through hydrogen bonding. The ordered and tight configuration of the PFOA chains onto the $\mathrm{In}_{2} \mathrm{O}_{3}$ surface favors direct hole oxidation with respect to water oxidation to hydroxyl radicals, and consequently the PFOA degradation occurs more efficiently on the surface of irradiated $\mathrm{In}_{2} \mathrm{O}_{3}$ than of $\mathrm{TiO}_{2}$. Moreover, $\mathrm{OH}$ radical-trapping experiments through electron paramagnetic resonance spectroscopy showed that the photogenerated holes are easily transformed into $\mathrm{OH}$ radicals on the $\mathrm{TiO}_{2}$ surface and only slowly react with adsorbed water or hydroxyl groups on the surface of $\operatorname{In}_{2} \mathrm{O}_{3}$. The addition of PFOA enhances the amount of $\mathrm{OH}$ radicals produced in the presence of $\mathrm{TiO}_{2}$ due to the electronwithdrawing ability of fluorine atoms reported elsewhere [121]. This does not help PFOA degradation, as $\mathrm{OH}$ radicals are not effective to this end [122], and holes are preferentially consumed to oxidize water. On the other hand, the already-small amount of $\mathrm{OH}$ radicals generated in the presence of $\operatorname{In}_{2} \mathrm{O}_{3}$ further decreases in the presence of PFOA. This indicates the favored direct hole oxidation of PFOA at the surface of $\operatorname{In}_{2} \mathrm{O}_{3}$.

Of several attempts to enhance the PFOA degradation rate in the presence of $\mathrm{TiO}_{2}$ under $\mathrm{UV}$ irradiation, $\mathrm{Pb}^{2+}$ modification showed the most promising results, providing a degradation rate 32.5 times higher with respect to the bare material [68]. Authors attributed 
the enhanced activity to the capability of $\mathrm{Pb}$ for acting as an electron trap, thus increasing the availability of holes for the degradation of PFOA.

Persulfate $\left(\mathrm{S}_{2} \mathrm{O}_{8}{ }^{2-}\right)$ has also been used as a promising alternative for the degradation of PFOA. The preliminary activation of persulfate is required to generate sulfate radicals (Equation (13)), which in turn may directly induce oxidation or react with water, producing $\mathrm{OH}$ radicals (Equation (14)) [123]. This reaction is slow at room temperature $\left(\mathrm{k}=2 \times 10^{-3} \mathrm{~s}^{-1}\right)$ but quickly proceeds at higher temperatures [124].

$$
\begin{gathered}
\mathrm{S}_{2} \mathrm{O}_{8}{ }^{2-} \rightarrow 2 \mathrm{SO}_{4}{ }^{-} \\
\mathrm{SO}_{4}{ }^{-}+\mathrm{H}_{2} \mathrm{O} \rightarrow \mathrm{SO}_{4}{ }^{2-}+\cdot \mathrm{OH}+\mathrm{H}^{+}
\end{gathered}
$$

The activation of persulfate can be performed through thermal energy. For instance, complete defluorination of PFOA $(0.1 \mathrm{mM})$ was observed after $18 \mathrm{~h}$ at $70{ }^{\circ} \mathrm{C}$ [125]. Several other methods to activate persulfate have been proposed to degrade PFAS, including ultraviolet, microwave, $\mathrm{Fe}^{2+}$, and ultrasound approaches. However, the highest defluorination efficiency was achieved by heat activation [126].

Sulfate radicals induce PFOA degradation but with a much lower defluorination ratio, indicating an insufficient degree of mineralization. Several short-chain perfluoroalkyl carboxylates (C2-C6) have been identified [127,128]. The proposed reaction mechanism proceeds with a sequential elimination of $\mathrm{CF}_{2}$ groups [129]. Decarboxylation of PFOA is induced by sulfate radical attack through the formation of a radical cation intermediate (Equations (15) and (16)).

$$
\begin{gathered}
\mathrm{SO}_{4}{ }^{-} \cdot+\mathrm{C}_{7} \mathrm{~F}_{15} \mathrm{COOH} \rightarrow \mathrm{SO}_{4}{ }^{2-}+\mathrm{C}_{7} \mathrm{~F}_{15} \mathrm{COOH}^{+} \\
\mathrm{C}_{7} \mathrm{~F}_{15} \mathrm{COOH}^{+} \cdot \rightarrow \mathrm{C}_{7} \mathrm{~F}_{15} \cdot+\mathrm{CO}_{2}+\mathrm{H}^{+}
\end{gathered}
$$

The resulting radical couples with an $\mathrm{OH}$ radical, producing the unstable alcohol intermediate which eventually evolves according to Equations (7)-(10).

\section{Direct Photolysis}

Given that PFAS does not absorb visible light and absorption is generally limited to the UVC region [130], the use of solar irradiation is not possible and artificial sources are required. In fact, the dissociation energy for C-F bonds can be up to $544 \mathrm{~kJ} / \mathrm{mol}$ [102], corresponding to photons of $220 \mathrm{~nm}$. UV light sources of wavelength $<220 \mathrm{~nm}$ and high power are somewhat less common than their UV-A or B counterparts. They have generally lower lifetime, require more specialized equipment and safety precautions, and as such the associated costs are higher. This is reflected by the scarcity of reports focusing on this approach present in literature. Nevertheless, important results can be found either in

\begin{tabular}{|c|c|c|c|c|c|}
\hline $\begin{array}{c}\text { Irradiation } \\
\text { Wavelength (nm) }\end{array}$ & $\begin{array}{c}\text { Power } \\
\text { (Electrical, W) }\end{array}$ & Substrates & Reaction Time & $\begin{array}{c}\text { Degradation/Defluorination } \\
\text { Yield (\%) }\end{array}$ & Ref. \\
\hline 254 & 200 & PFOA $1.35 \mathrm{mM}$ & $72 \mathrm{~h}$ & $89 / 33$ & [116] \\
\hline 254 & 15 & PFOA $0.025 \mathrm{mM}$ & $6 \mathrm{~h}$ & $13 / 2$ & [131] \\
\hline $\begin{array}{l}185 \text { (prevalent) } \\
254 \text { (prevalent) }\end{array}$ & 20 & PFOA $0.12-2.42 \mu \mathrm{M}$ & $3 \mathrm{~h}$ & $\begin{array}{l}87 / 21 \\
31 / 0.5\end{array}$ & [132] \\
\hline 185 & 15 & $\begin{array}{c}\text { PFOA } 60 \mu \mathrm{M} \\
\text { perfluoropropionic acid, }\end{array}$ & $2 \mathrm{~h}$ & $62 / 17$ & [133] \\
\hline $220-460$ & 200 & $\begin{array}{l}\text { perfluorobutyric acid, } \\
\text { perfluoropentanoic acid }\end{array}$ & $24 \mathrm{~h}$ & $16-24 / 9-12$ & [134] \\
\hline 254 & 36 & PFOA $0.024 \mathrm{mM}$ & $8 \mathrm{~h}$ & $20 / 9$ & [135] \\
\hline 254 & 24 & PFOA $1 \mathrm{mg} / \mathrm{L}$ & $24 \mathrm{~h}$ & $21 / 9$ & [136] \\
\hline
\end{tabular}
dedicated reports or extracted from photocatalysis papers where they appear as baseline or control experiments. Some results are collected in the Table 2 below:

Table 2. Direct photolysis of PFAS compounds in water. 
Although direct photolysis seems to be moderately effective for initiating degradation, the reported defluorination yields are quite low, indicating that complex mechanisms are taking place rather than simple photoinduced bond dissociation. Along with the problems related to equipment, the difficulties presented by the direct photolysis approach provide the motivation to investigate other methodologies, for example where light absorption is performed by a photocatalyst (as described in the previous section).

\section{Methods Based on a Sacrificial Radical Source}

A different approach involves the presence of a sacrificial agent in the solution, enabling pathways based on the generation of radical species. Among these latter, it is worth mentioning the use of aqueous electrons to perform reductive defluorination, as explored by $\mathrm{Qu}$ et al. [131]. These authors employed potassium iodide to generate hydrated electrons from a water-iodide complex under $254 \mathrm{~nm}$ wavelength irradiation from a $15 \mathrm{~W}$ lamp. A combination of photolysis and reduction by electrons then yielded a $96 \%$ defluorination for $0.025 \mathrm{mM}$ PFOA in a $12 \mathrm{~h}$ experiment. Another report along the same lines is that by Zhang et al. [137], though in this case aqueous electrons, along with hydroxyl and other radicals, were generated by the more exotic approach of irradiating water with $\gamma$-rays. In addition to mineralization of around $86 \%$ and nearly $100 \%$ defluorination for $20 \mathrm{mg} / \mathrm{L}$ PFOA in a $22 \mathrm{~h}$ experiment, the report highlights the synergistic effect of hydroxyl radicals and aqueous electrons, which are both necessary to achieve efficient removal. Indeed, hydroxyl radical-based processes such as Fenton, photo-Fenton, and hydrogen peroxide activation are ineffective due to the inactivity of $\mathrm{OH}^{\circ}$, as also recently clarified by Javed et al. [136], who found no significant difference in PFOA degradation under $\mathrm{UV}$ irradiation and $\mathrm{UV} / \mathrm{H}_{2} \mathrm{O}_{2}$. In contrast, several processes based on sulfate radicals $\left(\mathrm{SO}_{4}{ }^{\bullet-}\right)$, obtained by persulfate activation, have been reported to be effective, though defluorination efficiencies remain low. Hori et al. used a $200 \mathrm{~W}$ Xe-Hg UV-visible lamp to activate persulfate $(50 \mathrm{mM})$ for treating $1.35 \mathrm{mM}$ PFOA in a 4 h experiment, observing an 11-fold increase in decomposition with respect to direct photolysis [138]. Similarly, Chen and Zhang used UV-activated persulfate on PFOA, reporting that while using $185 \mathrm{~nm}$ irradiation, decomposition was proceeded by both direct photolysis and sulfate radicals, under $254 \mathrm{~nm}$ light the latter was the prevalent mechanism [139]. A step forward was made by introducing ferrous iron as a persulfate activator in the system, enabling a low activation energy pathway for the decomposition of persulfate to sulfate radicals [140]. Using this approach, Tran et al. recently reported $64 \%$ degradation of PFOA (initial concentration: $1.64 \mu \mathrm{M})$ in a $4 \mathrm{~h}$ anoxic experiment [141]. However, the role of light was not clarified and defluorination not discussed, leaving room for further investigations. A further effort in this direction was made by $\mathrm{Xu}$ et al. [11], who combined a $\mathrm{Ga}_{2} \mathrm{O}_{3}$ photocatalyst with peroxymonosulfate as a sulfate radical sacrificial source. Under illumination from either a $32 \mathrm{~W} 185 \mathrm{~nm}$ light or a $32 \mathrm{~W} 254 \mathrm{~nm}$ light, complete degradation of a PFOA solution in the $50 \mathrm{ng} / \mathrm{L}$ to $50 \mathrm{mg} / \mathrm{L}$ range was claimed, although defluorination was not quantified. A more detailed examination of persulfate-based methods (out of the scope of this work) is being currently studied, and can be found in a recent article by Yang et al. [142]. Overall, methods based on sacrificial radical sources look promising in terms of yields, but may have similar drawbacks to direct photolysis because radical generation is often performed by activation with the same artificial UVC light sources, with all its related problems. Furthermore, the sacrificial nature of the reagents used to generate the radicals implies extra costs with respect to direct photolysis or photocatalysis. In this respect, further work is needed not only to clarify the reaction mechanisms and improve efficiency but also to evaluate the economic viability and industrial scalability of this approach with respect to current methods or other methods under study. 


\section{Light Sources}

To date, the application of photocatalysis to PFAS compounds has mostly been performed by means of the use of artificial light sources of varying wavelengths of ultraviolet A (UVA 315-400 nm) using lamps with a light emission peak at $365 \mathrm{~nm}$, and ultraviolet C (UVC 100-280 nm) using lamps with peaks at 254 and $185 \mathrm{~nm}$ [54]. The wavelength of $185 \mathrm{~nm}$ itself can degrade PFAS, since the absorption of PFOA has been confirmed for this wavelength. However, this range of wavelength at the industrial level, because of the high costs, represents a market block for AOP as a possible approach for PFAS-contaminated wastewater [133].

The employment of UVA lamps with a peak at the wavelength of $365 \mathrm{~nm}$ has mostly been used in systems of power ranging from 125 to $300 \mathrm{~W}$ in $\mathrm{TiO}_{2}$-based photocatalysts with $\mathrm{Pt}, \mathrm{Pd}$, and $\mathrm{Ag}$ nanoparticles or in the presence of multi-wall carbon nanotubes (MWCNTs) [57,66]. For UVC $(254 \mathrm{~nm})$, studies report emission powers from 16 to $500 \mathrm{~W}$ for pure $\mathrm{TiO}_{2}, \mathrm{TiO}_{2}$ doped with $\mathrm{Cu}, \mathrm{Fe}$, and $\mathrm{Pb}$ ions, and composites with molecularly imprinted polymers. Studies have also been reported using $\mathrm{In}_{2} \mathrm{O}_{3}$ and $\mathrm{Ga}_{2} \mathrm{O}_{3}$ in sheaf, needle, microsphere, nanotube, and nanoparticle forms, as well doping with nitrogen and with $\mathrm{CeO}_{2}$ [78,82]. Applications using $\mathrm{ZnO}$ have been also reported [143].

Given the present situation, an advantage could be to move towards possible photocatalysts that can absorb in the near-UV range. Indeed, by using solar concentrators, the near-UV part of the solar spectrum is reflected and focused, thus permitting its utilization with photocatalysts. Anodized aluminum mirrors with special acrylic resin coatings are interesting examples for exploiting the near-UV part of the solar spectrum [144].

\section{Economic Aspects}

As the applications of the advanced oxidation process seem to be in an early stage in the field of PFAS remediation, to the best of our knowledge, an in-depth analysis regarding the costs of such methodologies has not yet been published.

State agency studies report an average cost of USD 2.00/gallon for PFAS treatment when considering the combined activity of GAC and AIX (anion exchange resins)) for infrastructure capacities from 2 to 50 million gallons per day (MGD) and with an initial investment from USD 3 to 120 million [145].

For budgeting PFAS management, the United States Environmental Protection Agency proposed a sequence of several necessary activities in the following order: Baseline monitoring $>$ Public engagement $>$ Regulatory engagement $>$ Bench or pilot testing $>$ Capital investment in full-scale treatment $>$ Operation and maintenance costs of full-scale treatment $>$ Long-term monitoring [146].

The same institution has a "Drinking water treatment technology unit cost model" and emphasizes the need for updating the model to be capable of addressing PFAS issues. The updating appears necessary because of the lack of consensus throughout the world regarding the acceptable levels of the diverse PFASs present in drinking water.

Olatunde et al. [147] undertook an economical evaluation on the applications of AOPs for degradation of PFAS substances, taking into consideration the stage of development of the technology, energy consumption, the time required to achieve $90 \%$ degradation of the substance, and the total volume of contaminated solution. Table 3 summarizes the results obtained with initial budgeting costs. The reported data show still an advantage in costs related to the use of direct photolysis, with the highest costs attributed to photocatalysis. However, the need to use radiation at a $185 \mathrm{~nm}$ wavelength imposes limitations to such applications in terms of lamp durability and safety. In the other hand, investments in photocatalysis research could lead to materials capable of efficiently degrading PFAS compounds with the positive feature of working under near UV-visible light. 
Table 3. Relative cost comparisons between the most successful employed techniques employed for PFAS degradation (adapted from [147]).

\begin{tabular}{cccccc}
\hline Technology & $\begin{array}{c}\text { Stage of } \\
\text { Development }\end{array}$ & $\begin{array}{c}\text { Energy } \\
\left(\mathbf{K W h} / \mathbf{m}^{\mathbf{3}}\right)\end{array}$ & $\begin{array}{c}\text { Relative Cost } \\
\text { (USD) }\end{array}$ & $\begin{array}{c}\text { Removal } \\
\text { Efficiency (\%) }\end{array}$ & $\begin{array}{c}\text { Time to 90\% } \\
\text { Degradation (min) }\end{array}$ \\
\hline $\begin{array}{c}\text { Photolysis }(185 \mathrm{~nm}) \\
\text { Photochemicals } \\
\text { (persulfates) }\end{array}$ & Emerging & 99 & 14 & 82 & 216 \\
$\begin{array}{c}\text { Photocatalysis (indium } \\
\text { oxides }+254 \mathrm{~nm})\end{array}$ & Research & 864 & 121 & 99 & 760 \\
\hline
\end{tabular}

\section{Conclusions}

The degradation of PFAS substances that contaminate water represents a strong challenge for the scientific, industrial, and regulation sectors. Great efforts to develop new photocatalysts able to efficiently degrade PFAS substances have been made. However, advances are still necessary to permit the full transfer of laboratory results to field applications in wastewater treatment plants. For example, photocatalysts based on indium or gallium have scarce prospects at a large scale, while some others need to be illuminated by high-power UV emission lamps that involve large costs and a limited lifetime. However, efforts have been made to develop environmentally friendly semiconductors such as zinc and titanium-based materials that, with appropriate doping or in composites, may be activated by near UV-visible radiation, thus making use of sunlight.

A shared study that highlights the sources of PFAS pollution and their evolution, while establishing intervention strategies for the further development of efficient and low-cost photocatalysts for large-scale production that favor the use of solar radiation, will allow us to effectively provide a solution for the PFAS contamination problem. The objective of this review paper is precisely to aid in this direction.

Author Contributions: Conceptualization, D.L., M.A.F., F.P., N.P., M.O., and A.M.; writing—original draft preparation, D.L., M.A.F., F.P., N.P., M.O., and A.M.; writing-review and editing, D.L., M.A.F., F.P., N.P., M.O., and A.M.; supervision, A.M. All authors have read and agreed to the published version of the manuscript.

Funding: This research was funded by the University of Trento, project ERiCSol.

Institutional Review Board Statement: Not Applicable.

Informed Consent Statement: Not Applicable.

Conflicts of Interest: The authors declare no conflict of interest.

\section{References}

1. Buck, R.C.; Franklin, J.; Berger, U.; Conder, J.M.; Cousins, I.T.; de Voogt, P.; Jensen, A.A.; Kannan, K.; Mabury, S.A.; van Leeuwen, S.P.J. Perfluoroalkyl and polyfluoroalkyl substances in the environment: Terminology, classification, and origins. Integr. Environ. Assess. Manag. 2011, 7, 513-541. [CrossRef]

2. Baran, J.R. Fluorinated Surfactants and Repellents, 2nd ed.Revised and Expanded Surfactant Science Series; American Chemical Society: Washington, DC, USA, 2001; Volume 123, p. 8882. [CrossRef]

3. Interstate Technology and Regulatory Council (ITRC), PFAS Technical and Regulatory Guidance Document and Fact. 2020. Available online: https: / pfas-1.itrcweb.org/ (accessed on 5 November 2020).

4. Kirk, M.; Smurthwaite, K.; Braeunig, J.; Trevenar, S.; D’Este, C.; Lucas, R.; Lal, A.; Korda, R.; Clements, A.; Mueller, J. The PFAS Health Study: Systematic Literature Review. 2018. Available online: https://rsph.anu.edu.au/files/PFAS\%20Health\%20Study\% 20Systematic\%20Review_1.pdf (accessed on 11 September 2021).

5. Wang, S.; Yang, Q.; Chen, F.; Sun, J.; Luo, K.; Yao, F.; Wang, X.; Wang, D.; Li, X.; Zeng, G. Photocatalytic degradation of perfluorooctanoic acid and perfluorooctane sulfonate in water: A critical review. Chem. Eng. J. 2017, 328, 927-942. [CrossRef]

6. Xu, Y.; Fletcher, T.; Pineda, D.; Lindh, C.H.; Nilsson, C.; Glynn, A.; Vogs, C.; Norström, K.; Lilja, K.; Jakobsson, K.; et al. Serum Half-Lives for Short- and Long-Chain Perfluoroalkyl Acids after Ceasing Exposure from Drinking Water Contaminated by Firefighting Foam. Environ. Health Perspect. 2021, 128, 77004. [CrossRef]

7. Kirsch, P. Front Matter. In Modern Fluoroorganic Chemistry; Wiley-VCH: Baden-Württemberg, Germany, 2004; pp. i-xii. [CrossRef] 
8. Guo, R.; Sim, W.-J.; Lee, E.-S.; Lee, J.-H.; Oh, J.-E. Evaluation of the fate of perfluoroalkyl compounds in wastewater treatment plants. Water Res. 2010, 44, 3476-3486. [CrossRef] [PubMed]

9. Li, Z.; Zhang, P.; Shao, T.; Li, X. $\operatorname{In}_{2} \mathrm{O}_{3}$ nanoporous nanosphere: A highly efficient photocatalyst for decomposition of perfluorooctanoic acid. Appl. Catal. B Environ. 2012, 125, 350-357. [CrossRef]

10. Li, X.; Zhang, P.; Jin, L.; Shao, T.; Li, Z.; Cao, J. Efficient Photocatalytic Decomposition of Perfluorooctanoic Acid by Indium Oxide and Its Mechanism. Environ. Sci. Technol. 2012, 46, 5528-5534. [CrossRef]

11. Xu, B.; Zhou, J.L.; Altaee, A.; Ahmed, M.B.; Johir, M.A.H.; Ren, J.; Li, X. Improved photocatalysis of perfluorooctanoic acid in water and wastewater by $\mathrm{Ga}_{2} \mathrm{O}_{3} / \mathrm{UV}$ system assisted by peroxymonosulfate. Chemosphere 2020, 239, 124722. [CrossRef]

12. Henry, B.J.; Carlin, J.P.; Hammerschmidt, J.A.; Buck, R.C.; Buxton, L.W.; Fiedler, H.; Seed, J.; Hernandez, O. A critical review of the application of polymer of low concern and regulatory criteria to fluoropolymers. Integr. Environ. Assess. Manag. 2018, 14, 316-334. [CrossRef]

13. Lindstrom, A.B.; Strynar, M.J.; Libelo, E.L. Polyfluorinated Compounds: Past, Present, and Future. Environ. Sci. Technol. 2011, 45, 7954-7961. [CrossRef]

14. Washington, J.W.; Jenkins, T.M.; Rankin, K.; Naile, J.E. Decades-Scale Degradation of Commercial, Side-Chain, FluorotelomerBased Polymers in Soils and Water. Environ. Sci. Technol. 2015, 49, 915-923. [CrossRef]

15. Glüge, J.; Scheringer, M.; Cousins, I.T.; DeWitt, J.C.; Goldenman, G.; Herzke, D.; Lohmann, R.; Ng, C.A.; Trier, X.; Wang, Z. An overview of the uses of per- and polyfluoroalkyl substances (PFAS). Environ. Sci. Process. Impacts 2020, 22, 2345-2373. [CrossRef]

16. C8 Science Panel. 2019. Available online: www.c8sciencepanel.org (accessed on 22 January 2020).

17. Emerging Chemical Risks in Europe-'PFAS'. Europen Environment Agency, 12 December 2019. Last modified 9 March 2021. Available online: https:/ / www.eea.europa.eu/publications/emerging-chemical-risks-in-europe (accessed on 31 March 2021). [CrossRef]

18. ATSDR. Toxicological Profile for Perfluoroalkyls Draft for Public Comment; US Dept. of Health and Human Sciences: Atlanta, GA, USA, 2018. Available online: https: / / www.atsdr.cdc.gov/toxprofiles/tp200.pdf (accessed on 15 April 2021).

19. WHO. Some Chemicals Used as Solvents and in Polymer Manufacture; WHO: Geneva, Switzerland, 2016; Volume 110, IARC Monographs on the Evaluation of Carcinogenic Risks to Humans; ISBN 978-92-832-0148-9. Available online: https://www.iarc.who. $\mathrm{int} /$ news-events/iarc-monographs-volume-110-some-chemicals-used-as-solvents-and-in-polymer-manufacture/ (accessed on 20 April 2021).

20. Vaughn, B.; Andrea, W.; Kyle, S. Perfluorooctanoic Acid (PFOA) Exposures and Incident Cancers among Adults Living Near a Chemical Plant. Environ. Health Perspect. 2013, 121, 1313-1318. [CrossRef]

21. Fenton, S.E.; Reiner, J.L.; Nakayama, S.F.; Delinsky, A.D.; Stanko, J.P.; Hines, E.P.; White, S.S.; Lindstrom, A.B.; Strynar, M.J.; Petropoulou, S.-S.E. Analysis of PFOA in dosed CD-1 mice. Part 2: Disposition of PFOA in tissues and fluids from pregnant and lactating mice and their pups. Reprod. Toxicol. 2009, 27, 365-372. [CrossRef]

22. White, S.; Stanko, P.; Kayoko, K.; Calafat, A.M.; Hines, E.P.; Fenton, S. Gestational and Chronic Low-Dose PFOA Exposures and Mammary Gland Growth and Differentiation in Three Generations of CD-1 Mice. Environ. Health Perspect. 2011, 119, 1070-1076. [CrossRef] [PubMed]

23. Saleh, N.B.; Khalid, A.; Tian, Y.; Ayres, C.; Sabaraya, I.V.; Pietari, J.; Hanigan, D.; Chowdhury, I.; Apul, O.G. Removal of poly- and per-fluoroalkyl substances from aqueous systems by nano-enabled water treatment strategies. Environ. Sci. Water Res. Technol. 2019, 5, 198-208. [CrossRef]

24. ECHA Guidance on Information Requirements and Chemical Safety Assessment. 2016. Available online: https://echa.europa. eu/guidance-documents / guidance-on-information-requirements-and-chemical-safety-assessment (accessed on 12 February 2020).

25. Fourth National Report on Human Exposure to Environmental Chemicals; 2021. Available online: https://www.cdc.gov/ exposurereport/pdf/FourthReport_UpdatedTables_Volume1_Mar2021-508.pdf (accessed on 30 April 2021).

26. Meegoda, J.N.; Kewalramani, J.A.; Li, B.; Marsh, R.W. A Review of the Applications, Environmental Release, and Remediation Technologies of Per- and Polyfluoroalkyl Substances. Int. J. Environ. Res. Public Heal. 2020, 17, 8117. [CrossRef] [PubMed]

27. Kucharzyk, K.H.; Darlington, R.; Benotti, M.; Deeb, R.; Hawley, E. Novel treatment technologies for PFAS compounds: A critical review. J. Environ. Manag. 2017, 204, 757-764. [CrossRef]

28. Mahinroosta, R.; Senevirathna, L. A review of the emerging treatment technologies for PFAS contaminated soils. J. Environ. Manag. 2020, 255, 109896. [CrossRef] [PubMed]

29. Appleman, T.D. The Removal of Poly- and Perfluoroalkyl Substances by North American Water Treatment Practices, Colorado School of Mines. 2012. Available online: http://hdl.handle.net/11124/78755 (accessed on 10 December 2020).

30. Lu, D.; Sha, S.; Luo, J.; Huang, Z.; Jackie, X.Z. Treatment train approaches for the remediation of per- and polyfluoroalkyl substances (PFAS): A critical review. J. Hazard. Mater. 2020, 386, 121963. [CrossRef]

31. Wanninayake, D.M. Comparison of currently available PFAS remediation technologies in water: A review. J. Environ. Manag. 2021, 283, 111977. [CrossRef]

32. Ross, I.; McDonough, J.; Miles, J.; Storch, P.; Thelakkat Kochunarayanan, P.; Kalve, E.; Hurst, J.; Dasgupta, S.; Burdick, J. A review of emerging technologies for remediation of PFASs. Remediat. J. 2018, 28, 101-126. [CrossRef]

33. Al Amin, M.; Sobhani, Z.; Liu, Y.; Dharmaraja, R.; Chadalavada, S.; Naidu, R.; Chalker, J.M.; Fang, C. Recent advances in the analysis of per- and polyfluoroalkyl substances (PFAS)—A review. Environ. Technol. Innov. 2020, 19, 100879. [CrossRef] 
34. Jahnke, A.; Berger, U. Trace analysis of per- and polyfluorinated alkyl substances in various matrices-How do current methods perform? J. Chromatogr. A 2009, 1216, 410-421. [CrossRef] [PubMed]

35. Backe, W.J.; Day, T.C.; Field, J.A. Zwitterionic, Cationic, and Anionic Fluorinated Chemicals in Aqueous Film Forming Foam Formulations and Groundwater from U.S. Military Bases by Nonaqueous Large-Volume Injection HPLC-MS/MS. Environ. Sci. Technol. 2013, 47, 5226-5234. [CrossRef] [PubMed]

36. Kaboré, H.A.; Vo Duy, S.; Munoz, G.; Méité, L.; Desrosiers, M.; Liu, J.; Sory, T.K.; Sauvé, S. Worldwide drinking water occurrence and levels of newly-identified perfluoroalkyl and polyfluoroalkyl substances. Sci. Total Environ. 2018, 616-617, 1089-1100. [CrossRef] [PubMed]

37. Barzen-Hanson, K.A.; Field, J.A. Discovery and Implications of C2 and C3 Perfluoroalkyl Sulfonates in Aqueous Film-Forming Foams and Groundwater. Environ. Sci. Technol. Lett. 2015, 2, 95-99. [CrossRef]

38. Yeung, L.W.Y.; Stadey, C.; Mabury, S.A. Simultaneous analysis of perfluoroalkyl and polyfluoroalkyl substances including ultrashort-chain $\mathrm{C} 2$ and $\mathrm{C} 3$ compounds in rain and river water samples by ultra performance convergence chromatography. $J$. Chromatogr. A 2017, 1522, 78-85. [CrossRef]

39. Shao, M.; Ding, G.; Zhang, J.; Wei, L.; Xue, H.; Zhang, N.; Li, Y.; Chen, G.; Sun, Y. Occurrence and distribution of perfluoroalkyl substances (PFASs) in surface water and bottom water of the Shuangtaizi Estuary, China. Environ. Pollut. 2016, 216, 675-681. [CrossRef] [PubMed]

40. Janda, J.; Nödler, K.; Brauch, H.-J.; Zwiener, C.; Lange, F.T. Robust trace analysis of polar (C2-C8) perfluorinated carboxylic acids by liquid chromatography-tandem mass spectrometry: Method development and application to surface water, groundwater and drinking water. Environ. Sci. Pollut. Res. 2019, 26, 7326-7336. [CrossRef]

41. Gellrich, V.; Brunn, H.; Stahl, T. Perfluoroalkyl and polyfluoroalkyl substances (PFASs) in mineral water and tap water. J. Environ. Sci. Health Part A 2013, 48, 129-135. [CrossRef]

42. Liu, Y.; Pereira, A.D.S.; Martin, J.W. Discovery of C5-C17 Poly- and Perfluoroalkyl Substances in Water by In-Line SPE-HPLCOrbitrap with In-Source Fragmentation Flagging. Anal. Chem. 2015, 87, 4260-4268. [CrossRef]

43. Zhang, X.; Niu, H.; Pan, Y.; Shi, Y.; Cai, Y. Chitosan-Coated Octadecyl-Functionalized Magnetite Nanoparticles: Preparation and Application in Extraction of Trace Pollutants from Environmental Water Samples. Anal. Chem. 2010, 82, 2363-2371. [CrossRef]

44. Xia, W.; Wan, Y.-J.; Wang, X.; Li, Y.; Yang, W.-J.; Wang, C.-X.; Xu, S. Sensitive bioassay for detection of PPAR $\alpha$ potentially hazardous ligands with gold nanoparticle probe. J. Hazard. Mater. 2011, 192, 1148-1154. [CrossRef] [PubMed]

45. Takayose, M.; Akamatsu, K.; Nawafune, H.; Murashima, T.; Matsui, J. Colorimetric Detection of Perfluorooctanoic Acid (PFOA) Utilizing Polystyrene-Modified Gold Nanoparticles. Anal. Lett. 2012, 45, 2856-2864. [CrossRef]

46. Niu, H.; Wang, S.; Zhou, Z.; Ma, Y.; Ma, X.; Cai, Y. Sensitive Colorimetric Visualization of Perfluorinated Compounds Using Poly(ethylene glycol) and Perfluorinated Thiols Modified Gold Nanoparticles. Anal. Chem. 2014, 86, 4170-4177. [CrossRef] [PubMed]

47. Wang, Z.; Cousins, I.T.; Scheringer, M.; Buck, R.C.; Hungerbühler, K. Global emission inventories for C4-C14 perfluoroalkyl carboxylic acid (PFCA) homologues from 1951 to 2030, Part I: Production and emissions from quantifiable sources. Environ. Int. 2014, 70, 62-75. [CrossRef] [PubMed]

48. Fang, C.; Megharaj, M.; Naidu, R. Surface-enhanced Raman scattering (SERS) detection of fluorosurfactants in firefighting foams. RSC Adv. 2016, 6, 11140-11145. [CrossRef]

49. Okaru, A.O.; Brunner, T.S.; Ackermann, S.M.; Kuballa, T.; Walch, S.G.; Kohl-Himmelseher, M.; Lachenmeier, D.W. Application of ${ }^{19}$ F NMR Spectroscopy for Content Determination of Fluorinated Pharmaceuticals. J. Anal. Methods Chem. 2017, $2017,9206297$. [CrossRef]

50. Guo, W.; Jin, L.; Hu, S.; Guo, Q. Method Development for the Determination of Total Fluorine in Foods by Tandem Inductively Coupled Plasma Mass Spectrometry with a Mass-Shift Strategy. J. Agric. Food Chem. 2017, 65, 3406-3412. [CrossRef]

51. Boča, M.; Barborík, P.; Mičušík, M.; Omastová, M. X-ray photoelectron spectroscopy as detection tool for coordinated or uncoordinated fluorine atoms demonstrated on fluoride systems NaF, K2TaF7, K3TaF8, K2ZrF6, Na7Zr6F31 and K3ZrF7. Solid State Sci. 2012, 14, 828-832. [CrossRef]

52. Li, F.; Duan, J.; Tian, S.; Ji, H.; Zhu, Y.; Wei, Z.; Zhao, D. Short-chain per- and polyfluoroalkyl substances in aquatic systems: Occurrence, impacts and treatment. Chem. Eng. J. 2020, 380, 122506. [CrossRef]

53. Zhang, W.; Zhang, D.; Liang, Y. Nanotechnology in remediation of water contaminated by poly- and perfluoroalkyl substances: A review. Environ. Pollut. 2019, 247, 266-276. [CrossRef] [PubMed]

54. Xu, B.; Ahmed, M.B.; Zhou, J.L.; Altaee, A.; Wu, M.; Xu, G. Photocatalytic removal of perfluoroalkyl substances from water and wastewater: Mechanism, kinetics and controlling factors. Chem. Eng. J. 2017, 5, 1-9. [CrossRef] [PubMed]

55. Liu, X.; Wei, W.; Xu, J.; Wang, D.; Song, L.; Ni, B.-J. Photochemical decomposition of perfluorochemicals in contaminated water. Water Res. 2020, 186, 116311. [CrossRef]

56. Panchangam, S.C.; Lin, A.Y.-C.; Shaik, K.L.; Lin, C.-F. Decomposition of perfluorocarboxylic acids (PFCAs) by heterogeneous photocatalysis in acidic aqueous medium. Chemosphere 2009, 77, 242-248. [CrossRef]

57. Chen, M.-J.; Lo, S.-L.; Lee, Y.-C.; Huang, C.-C. Photocatalytic decomposition of perfluorooctanoic acid by transition-metal modified titanium dioxide. J. Hazard. Mater. 2015, 288, 168-175. [CrossRef] [PubMed]

58. Chen, Y.-C.; Lo, S.-L.; Kuo, J. Effects of titanate nanotubes synthesized by a microwave hydrothermal method on photocatalytic decomposition of perfluorooctanoic acid. Water Res. 2011, 45, 4131-4140. [CrossRef] 
59. Sansotera, M.; Persico, F.; Pirola, C.; Navarrini, W.; Di Michele, A.; Bianchi, C.L. Decomposition of perfluorooctanoic acid photocatalyzed by titanium dioxide: Chemical modification of the catalyst surface induced by fluoride ions. Appl. Catal. B Environ. 2014, 148-149, 29-35. [CrossRef]

60. Wang, Y.; Zhang, P. Photocatalytic decomposition of perfluorooctanoic acid (PFOA) by $\mathrm{TiO}_{2}$ in the presence of oxalic acid. J. Hazard. Mater. 2011, 192, 1869-1875. [CrossRef]

61. Song, C.; Chen, P.; Wang, C.; Zhu, L. Photodegradation of perfluorooctanoic acid by synthesized TiO $2-\mathrm{MWCNT}$ composites under 365nm UV irradiation. Chemosphere 2012, 86, 853-859. [CrossRef]

62. Rivero, M.J.; Ribao, P.; Gomez-Ruiz, B.; Urtiaga, A.; Ortiz, I. Comparative performance of $\mathrm{TiO}_{2}-\mathrm{rGO}$ photocatalyst in the degradation of dichloroacetic and perfluorooctanoic acids. Sep. Purif. Technol. 2020, 240, 116637. [CrossRef]

63. Gomez-Ruiz, B.; Ribao, P.; Diban, N.; Rivero, M.J.; Ortiz, I.; Urtiaga, A. Photocatalytic degradation and mineralization of perfluorooctanoic acid (PFOA) using a composite $\mathrm{TiO}_{2}-\mathrm{rGO}$ catalyst. J. Hazard. Mater. 2018, 344, 950-957. [CrossRef] [PubMed]

64. Zhu, C.; Xu, J.; Song, S.; Wang, J.; Li, Y.; Liu, R.; Shen, Y. $\mathrm{TiO}_{2}$ quantum dots loaded sulfonated graphene aerogel for effective adsorption-photocatalysis of PFOA. Sci. Total Environ. 2020, 698, 134275. [CrossRef] [PubMed]

65. Wu, Y.; Li, Y.; Tian, A.; Mao, K.; Liu, J. Selective Removal of Perfluorooctanoic Acid Using Molecularly Imprinted PolymerModified $\mathrm{TiO}_{2}$ Nanotube Arrays. Int. J. Photoenergy 2016, 2016, 7368795. [CrossRef]

66. Li, M.; Yu, Z.; Liu, Q.; Sun, L.; Huang, W. Photocatalytic decomposition of perfluorooctanoic acid by noble metallic nanoparticles modified $\mathrm{TiO}_{2}$. Chem. Eng. J. 2016, 286, 232-238. [CrossRef]

67. Weon, S.; Suh, M.-J.; Chu, C.; Huang, D.; Stavitski, E.; Kim, J.-H. Site-Selective Loading of Single-Atom Pt on TiO 2 for Photocatalytic Oxidation and Reductive Hydrodefluorination. ACS ESET Eng. 2021, 1, 512-522. [CrossRef]

68. Chen, M.-J.; Lo, S.-L.; Lee, Y.-C.; Kuo, J.; Wu, C.-H. Decomposition of perfluorooctanoic acid by ultraviolet light irradiation with Pb-modified titanium dioxide. J. Hazard. Mater. 2016, 303, 111-118. [CrossRef] [PubMed]

69. Li, F.; Wei, Z.; He, K.; Blaney, L.; Cheng, X.; Xu, T.; Liu, W.; Zhao, D. A concentrate-and-destroy technique for degradation of perfluorooctanoic acid in water using a new adsorptive photocatalyst. Water Res. 2020, 185, 116219. [CrossRef]

70. Zhu, Y.; Xu, T.; Zhao, D.; Li, F.; Liu, W.; Wang, B.; An, B. Adsorption and solid-phase photocatalytic degradation of perfluorooctane sulfonate in water using gallium-doped carbon-modified titanate nanotubes. Chem. Eng. J. 2021, 421, 129676. [CrossRef]

71. Abada, B.; Alivio, T.E.G.; Shao, Y.; O’Loughlin, T.E.; Klemashevich, C.; Banerjee, S.; Jayaraman, A.; Chu, K.-H. Photodegradation of fluorotelomer carboxylic 5:3 acid and perfluorooctanoic acid using zinc oxide. Environ. Pollut. 2018, 243, 637-644. [CrossRef]

72. Ong, C.B.; Mohammad, A.W.; Ng, L.Y.; Mahmoudi, E.; Azizkhani, S.; Hayati Hairom, N.H. Solar photocatalytic and surface enhancement of ZnO/rGO nanocomposite: Degradation of perfluorooctanoic acid and dye. Process Saf. Environ. Prot. 2017, 112, 298-307. [CrossRef]

73. Zhao, B.; Zhang, P. Photocatalytic decomposition of perfluorooctanoic acid with $\beta-\mathrm{Ga}_{2} \mathrm{O}_{3}$ wide bandgap photocatalyst. Catal. Commun. 2009, 10, 1184-1187. [CrossRef]

74. Shao, T.; Zhang, P.; Li, Z.; Jin, L. Photocatalytic decomposition of perfluorooctanoic acid in pure water and wastewater by needle-like nanostructured gallium oxide. Chin. J. Catal. 2013, 34, 1551-1559. [CrossRef]

75. Shao, T.; Zhang, P.; Jin, L.; Li, Z. Photocatalytic decomposition of perfluorooctanoic acid in pure water and sewage water by nanostructured gallium oxide. Appl. Catal. B Environ. 2013, 142-143, 654-661. [CrossRef]

76. Zhao, B.; Li, X.; Yang, L.; Wang, F.; Li, J.; Xia, W.; Li, W.; Zhou, L.; Zhao, C. B-Ga $\mathrm{O}_{3}$ Nanorod Synthesis with a One-step Microwave Irradiation Hydrothermal Method and its Efficient Photocatalytic Degradation for Perfluorooctanoic Acid. Photochem. Photobiol. 2015, 91, 42-47. [CrossRef]

77. Tan, X.; Chen, G.; Xing, D.; Ding, W.; Liu, H.; Li, T.; Huang, Y. Indium-modified $\mathrm{Ga}_{2} \mathrm{O}_{3}$ hierarchical nanosheets as efficient photocatalysts for the degradation of perfluorooctanoic acid. Environ. Sci. Nano 2020, 7, 2229-2239. [CrossRef]

78. Li, Z.; Zhang, P.; Shao, T.; Wang, J.; Jin, L.; Li, X. Different nanostructured $\operatorname{In}_{2} \mathrm{O}_{3}$ for photocatalytic decomposition of perfluorooctanoic acid (PFOA). J. Hazard. Mater. 2013, 260, 40-46. [CrossRef]

79. Li, Z.; Zhang, P.; Li, J.; Shao, T.; Wang, J.; Jin, L. Synthesis of $\mathrm{In}_{2} \mathrm{O}_{3}$ porous nanoplates for photocatalytic decomposition of perfluorooctanoic acid (PFOA). Catal. Commun. 2014, 43, 42-46. [CrossRef]

80. Liu, X.; Xu, B.; Duan, X.; Hao, Q.; Wei, W.; Wang, S.; Ni, B.-J. Facile preparation of hydrophilic $\operatorname{In}_{2} \mathrm{O}_{3}$ nanospheres and rods with improved performances for photocatalytic degradation of PFOA. Environ. Sci. Nano 2021, 8, 1010-1018. [CrossRef]

81. Li, Z.; Zhang, P.; Li, J.; Shao, T.; Jin, L. Synthesis of $\operatorname{In}_{2} \mathrm{O}_{3}$-graphene composites and their photocatalytic performance towards perfluorooctanoic acid decomposition. J. Photochem. Photobiol. A Chem. 2013, 271, 111-116. [CrossRef]

82. Jiang, F.; Zhao, H.; Chen, H.; Xu, C.; Chen, J. Enhancement of photocatalytic decomposition of perfluorooctanoic acid on $\mathrm{CeO}_{2} / \mathrm{In}_{2} \mathrm{O}_{3}$. RSC Adv. 2016, 6, 72015-72021. [CrossRef]

83. Wu, Y.; Li, Y.; Fang, C.; Li, C. Highly Efficient Degradation of Perfluorooctanoic Acid over a MnOx-Modified Oxygen-Vacancy-Rich $\mathrm{In}_{2} \mathrm{O}_{3}$ Photocatalyst. ChemCatChem 2019, 11, 2297-2303. [CrossRef]

84. Xu, J.; Wu, M.; Yang, J.; Wang, Z.; Chen, M.; Teng, F. Efficient photocatalytic degradation of perfluorooctanoic acid by a wide band gap p-block metal oxyhydroxide InOOH. Appl. Surf. Sci. 2017, 416, 587-592. [CrossRef]

85. Verma, S.; Mezgebe, B.; Sahle-Demessie, E.; Nadagouda, M.N. Photooxidative decomposition and defluorination of perfluorooctanoic acid (PFOA) using an innovative technology of UV-vis/ZnxCu1-xFe $\mathrm{O}_{4}$ / oxalic acid. Chemosphere 2021, $280,130660$. [CrossRef] 
86. Yang, Y.; Zhang, C.; Lai, C.; Zeng, G.; Huang, D.; Cheng, M.; Wang, J.; Chen, F.; Zhou, C.; Xiong, W. BiOX (X = Cl, Br, I) photocatalytic nanomaterials: Applications for fuels and environmental management. Adv. Colloid Interface Sci. 2018, $254,76-93$. [CrossRef]

87. Song, Z.; Dong, X.; Wang, N.; Zhu, L.; Luo, Z.; Fang, J.; Xiong, C. Efficient photocatalytic defluorination of perfluorooctanoic acid over $\mathrm{BiOCl}$ nanosheets via a hole direct oxidation mechanism. Chem. Eng. J. 2017, 317, 925-934. [CrossRef]

88. Song, Z.; Dong, X.; Fang, J.; Xiong, C.; Wang, N.; Tang, X. Improved photocatalytic degradation of perfluorooctanoic acid on oxygen vacancies-tunable bismuth oxychloride nanosheets prepared by a facile hydrolysis. J. Hazard. Mater. 2019, 377, 371-380. [CrossRef]

89. Wang, J.; Cao, C.; Zhang, Y.; Zhang, Y.; Zhu, L. Underneath mechanisms into the super effective degradation of PFOA by BiOF nanosheets with tunable oxygen vacancies on exposed (101) facets. Appl. Catal. B Environ. 2021, 286, 3-5. [CrossRef]

90. Li, T.; Wang, C.; Wang, T.; Zhu, L. Highly efficient photocatalytic degradation toward perfluorooctanoic acid by bromine doped BiOI with high exposure of (001) facet. Appl. Catal. B Environ. 2020, 268, 118442. [CrossRef]

91. Wang, J.; Wang, Y.; Cao, C.; Zhang, Y.; Zhang, Y.; Zhu, L. Decomposition of highly persistent perfluorooctanoic acid by hollow Bi/BiOI1-xFx: Synergistic effects of surface plasmon resonance and modified band structures. J. Hazard. Mater. 2021, $402,123459$. [CrossRef] [PubMed]

92. Wang, J.; Cao, C.; Wang, Y.; Wang, Y.; Sun, B.; Zhu, L. In situ preparation of p-n BiOI@Bi ${ }_{5} \mathrm{O}_{7} \mathrm{I}$ heterojunction for enhanced PFOA photocatalytic degradation under simulated solar light irradiation. Chem. Eng. J. 2020, 391, 123530. [CrossRef]

93. Yang, Y.; Ji, W.; Li, X.; Zheng, Z.; Bi, F.; Yang, M.; Xu, J.; Zhang, X. Insights into the degradation mechanism of perfluorooctanoic acid under visible-light irradiation through fabricating flower-shaped $\mathrm{Bi}_{5} \mathrm{O}_{7} \mathrm{I} / \mathrm{ZnO}$ n-n heterojunction microspheres. Chem. Eng. J. 2021, 420, 129934. [CrossRef]

94. Sahu, S.P.; Qanbarzadeh, M.; Ateia, M.; Torkzadeh, H.; Maroli, A.S.; Cates, E.L. Rapid Degradation and Mineralization of Perfluorooctanoic Acid by a New Petitjeanite $\mathrm{Bi}_{3} \mathrm{O}(\mathrm{OH})\left(\mathrm{PO}_{4}\right)_{2}$ Microparticle Ultraviolet Photocatalyst. Environ. Sci. Technol. Lett. 2018, 5, 533-538. [CrossRef]

95. Xu, T.; Zhu, Y.; Duan, J.; Xia, Y.; Tong, T.; Zhang, L.; Zhao, D. Enhanced photocatalytic degradation of perfluorooctanoic acid using carbon-modified bismuth phosphate composite: Effectiveness, material synergy and roles of carbon. Chem. Eng. J. 2020, 395, 124991. [CrossRef]

96. Xu, T.; Ji, H.; Gu, Y.; Tong, T.; Xia, Y.; Zhang, L.; Zhao, D. Enhanced adsorption and photocatalytic degradation of perfluorooctanoic acid in water using iron (hydr)oxides/carbon sphere composite. Chem. Eng. J. 2020, 388, 124230. [CrossRef]

97. Duan, L.; Wang, B.; Heck, K.; Guo, S.; Clark, C.A.; Arredondo, J.; Wang, M.; Senftle, T.P.; Westerhoff, P.; Wen, X.; et al. Efficient Photocatalytic PFOA Degradation over Boron Nitride. Environ. Sci. Technol. Lett. 2020, 7, 613-619. [CrossRef]

98. You, X.; Yu, L.; Xiao, F.; Wu, S.; Yang, C.; Cheng, J. Synthesis of phosphotungstic acid-supported bimodal mesoporous silica-based catalyst for defluorination of aqueous perfluorooctanoic acid under vacuum UV irradiation. Chem. Eng. J. 2018, 335, 812-821. [CrossRef]

99. Tang, H.; Zhang, W.; Meng, Y.; Xia, S. A direct Z-scheme heterojunction with boosted transportation of photogenerated charge carriers for highly efficient photodegradation of PFOA: Reaction kinetics and mechanism. Appl. Catal. B Environ. 2021, 285, 119851. [CrossRef]

100. Banks, D.; Jun, B.-M.; Heo, J.; Her, N.; Park, C.M.; Yoon, Y. Selected advanced water treatment technologies for perfluoroalkyl and polyfluoroalkyl substances: A review. Sep. Purif. Technol. 2020, 231, 115929. [CrossRef]

101. Xu, B.; Liu, S.; Zhou, J.L.; Zheng, C.; Weifeng, J.; Chen, B.; Zhang, T.; Qiu, W. PFAS and their substitutes in groundwater: Occurrence, transformation and remediation. J. Hazard. Mater. 2021, 412, 125159. [CrossRef]

102. Merino, N.; Qu, Y.; Deeb, R.A.; Hawley, E.L.; Hoffmann, M.R.; Mahendra, S. Degradation and Removal Methods for Perfluoroalkyl and Polyfluoroalkyl Substances in Water. Environ. Eng. Sci. 2016, 33, 615-649. [CrossRef]

103. Ahmed, M.B.; Alam, M.M.; Zhou, J.L.; Xu, B.; Johir, M.A.H.; Karmakar, A.K.; Rahman, M.S.; Hossen, J.; Hasan, A.T.M.K.; Moni, M.A. Advanced treatment technologies efficacies and mechanism of per- and poly-fluoroalkyl substances removal from water. Process Saf. Environ. Prot. 2020, 136, 1-14. [CrossRef]

104. Gatto, S.; Sansotera, M.; Persico, F.; Gola, M.; Pirola, C.; Panzeri, W.; Navarrini, W.; Bianchi, C.L. Surface fluorination on TiO 2 catalyst induced by photodegradation of perfluorooctanoic acid. Catal. Today 2015, 241, 8-14. [CrossRef]

105. Parrino, F.; De Pasquale, C.; Palmisano, L. Influence of Surface-Related Phenomena on Mechanism, Selectivity, and Conversion of $\mathrm{TiO}_{2}$-Induced Photocatalytic Reactions. ChemSusChem 2019, 12, 589-602. [CrossRef] [PubMed]

106. Zaggia, A.; Ameduri, B. Recent advances on synthesis of potentially non-bioaccumulable fluorinated surfactants. Curr. Opin. Colloid Interface Sci. 2012, 17, 188-195. [CrossRef]

107. Panchangam, S.C.; Lin, A.Y.-C.; Tsai, J.-H.; Lin, C.-F. Sonication-assisted photocatalytic decomposition of perfluorooctanoic acid. Chemosphere 2009, 75, 654-660. [CrossRef]

108. Lin, H.; Niu, J.; Ding, S.; Zhang, L. Electrochemical degradation of perfluorooctanoic acid (PFOA) by $\mathrm{Ti} / \mathrm{SnO}_{2}-\mathrm{Sb}, \mathrm{Ti} / \mathrm{SnO}{ }_{2}-$ $\mathrm{Sb} / \mathrm{PbO}_{2}$ and $\mathrm{Ti} / \mathrm{SnO}_{2}-\mathrm{Sb} / \mathrm{MnO}_{2}$ anodes. Water Res. 2012, 46, 2281-2289. [CrossRef]

109. Kutsuna, S.; Hori, H. Rate constants for aqueous-phase reactions of $\mathrm{SO}_{4}{ }^{-}$with $\mathrm{C}_{2} \mathrm{~F}_{5} \mathrm{C}(\mathrm{O}) \mathrm{O}^{-}$and $\mathrm{C}_{3} \mathrm{~F}_{7} \mathrm{C}(\mathrm{O}) \mathrm{O}^{-}$at $298 \mathrm{~K}$. Int. J. Chem. Kinet. 2007, 39, 276-288. [CrossRef] 
110. Talaeemashhadi, S.; Sansotera, M.; Gambarotti, C.; Famulari, A.; Bianchi, C.L.; Antonio Guarda, P.; Navarrini, W. Functionalization of multi-walled carbon nanotubes with perfluoropolyether peroxide to produce superhydrophobic properties. Carbon N. Y. 2013, 59, 150-159. [CrossRef]

111. de Bruyn, W.J.; Shorter, J.A.; Davidovits, P.; Worsnop, D.R.; Zahniser, M.S.; Kolb, C.E. Uptake of Haloacetyl and Carbonyl Halides by Water Surfaces. Environ. Sci. Technol. 1995, 29, 1179-1185. [CrossRef] [PubMed]

112. Sansotera, M.; Navarrini, W.; Gola, M.; Bianchi, C.L.; Wormald, P.; Famulari, A.; Avataneo, M. Peroxidic perfluoropolyether for the covalent binding of perfluoropolyether chains on carbon black surface. J. Fluor. Chem. 2011, 132, 1254-1261. [CrossRef]

113. Wallington, T.J.; Ellermann, T.; Nielsen, O.J.; Sehested, J. Atmospheric Chemistry of FCOx Radicals: UV Spectra and Self-Reaction Kinetics of FCO and $\mathrm{FC}(\mathrm{O}) \mathrm{O}_{2}$ and Kinetics of Some Reactions of FCOx with $\mathrm{O}_{2}, \mathrm{O}_{3}$, and $\mathrm{NO}$ at 296 K. J. Phys. Chem. 1994, 98, 2346-2356. [CrossRef]

114. Sansotera, M.; Navarrini, W.; Magagnin, L.; Bianchi, C.L.; Sanguineti, A.; Metrangolo, P.; Resnati, G. Hydrophobic carbonaceous materials obtained by covalent bonding of perfluorocarbon and perfluoropolyether chains. J. Mater. Chem. 2010, 20, 8607-8616. [CrossRef]

115. Giri, R.R.; Ozaki, H.; Morigaki, T.; Taniguchi, S.; Takanami, R. UV photolysis of perfluorooctanoic acid (PFOA) in dilute aqueous solution. Water Sci. Technol. 2011, 63, 276-282. [CrossRef]

116. Hori, H.; Hayakawa, E.; Einaga, H.; Kutsuna, S.; Koike, K.; Ibusuki, T.; Kiatagawa, H.; Arakawa, R. Decomposition of Environmentally Persistent Perfluorooctanoic Acid in Water by Photochemical Approaches. Environ. Sci. Technol. 2004, 38, 6118-6124. [CrossRef] [PubMed]

117. Cao, M.H.; Wang, B.B.; Yu, H.S.; Wang, L.L.; Yuan, S.H.; Chen, J. Photochemical decomposition of perfluorooctanoic acid in aqueous periodate with VUV and UV light irradiation. J. Hazard. Mater. 2010, 179, 1143-1146. [CrossRef]

118. Vecitis, C.D.; Park, H.; Cheng, J.; Mader, B.T.; Hoffmann, M.R. Treatment technologies for aqueous perfluorooctanesulfonate (PFOS) and perfluorooctanoate (PFOA). Front. Environ. Sci. Eng. China 2009, 3, 129-151. [CrossRef]

119. Dillert, R.; Bahnemann, D.; Hidaka, H. Light-induced degradation of perfluorocarboxylic acids in the presence of titanium dioxide. Chemosphere 2007, 67, 785-792. [CrossRef] [PubMed]

120. Choi, W.; Hoffmann, M.R. Novel Photocatalytic Mechanisms for $\mathrm{CHCl}_{3}, \mathrm{CHBr}_{3}$, and $\mathrm{CCl}_{3} \mathrm{CO}_{2}{ }^{-}$Degradation and the Fate of Photogenerated Trihalomethyl Radicals on $\mathrm{TiO}_{2}$. Environ. Sci. Technol. 1997, 31, 89-95. [CrossRef]

121. Fessi, N.; Nsib, M.F.; Cardenas, L.; Guillard, C.; Dappozze, F.; Houas, A.; Parrino, F.; Palmisano, L.; Ledoux, G.; Amans, D.; et al. Surface and Electronic Features of Fluorinated $\mathrm{TiO}_{2}$ and Their Influence on the Photocatalytic Degradation of 1Methylnaphthalene. J. Phys. Chem. C 2020, 124, 11456-11468. [CrossRef]

122. Schröder, H.F.; Meesters, R.J.W. Stability of fluorinated surfactants in advanced oxidation processes-A follow up of degradation products using flow injection-mass spectrometry, liquid chromatography-mass spectrometry and liquid chromatographymultiple stage mass spectrometry. J. Chromatogr. A 2005, 1082, 110-119. [CrossRef]

123. Yang, S.; Wang, P.; Yang, X.; Shan, L.; Zhang, W.; Shao, X.; Niu, R. Degradation efficiencies of azo dye Acid Orange 7 by the interaction of heat, UV and anions with common oxidants: Persulfate, peroxymonosulfate and hydrogen peroxide. J. Hazard. Mater. 2010, 179, 552-558. [CrossRef] [PubMed]

124. Zhao, D.; Liao, X.; Yan, X.; Huling, S.G.; Chai, T.; Tao, H. Effect and mechanism of persulfate activated by different methods for PAHs removal in soil. J. Hazard. Mater. 2013, 254-255, 228-235. [CrossRef] [PubMed]

125. Santos, A.; Rodríguez, S.; Pardo, F.; Romero, A. Use of Fenton reagent combined with humic acids for the removal of PFOA from contaminated water. Sci. Total Environ. 2016, 563-564, 657-663. [CrossRef] [PubMed]

126. Yang, S.; Cheng, J.; Sun, J.; Hu, Y.; Liang, X. Defluorination of Aqueous Perfluorooctanesulfonate by Activated Persulfate Oxidation. PLOS ONE 2013, 8, e74877.

127. Lee, Y.-C.; Lo, S.-L.; Chiueh, P.-T.; Liou, Y.-H.; Chen, M.-L. Microwave-hydrothermal decomposition of perfluorooctanoic acid in water by iron-activated persulfate oxidation. Water Res. 2010, 44, 886-892. [CrossRef]

128. Lee, Y.; Lo, S.; Kuo, J.; Hsieh, C. Decomposition of perfluorooctanoic acid by microwaveactivated persulfate: Effects of temperature, $\mathrm{pH}$, and chloride ions. Front. Environ. Sci. Eng. 2012, 6, 17-25. [CrossRef]

129. Kim, T.-H.; Lee, S.-H.; Kim, H.Y.; Doudrick, K.; Yu, S.; Kim, S.D. Decomposition of perfluorooctane sulfonate (PFOS) using a hybrid process with electron beam and chemical oxidants. Chem. Eng. J. 2019, 361, 1363-1370. [CrossRef]

130. Taniyasu, S.; Yamashita, N.; Yamazaki, E.; Petrick, G.; Kannan, K. The environmental photolysis of perfluorooctanesulfonate, perfluorooctanoate, and related fluorochemicals. Chemosphere 2013, 90, 1686-1692. [CrossRef] [PubMed]

131. Qu, Y.; Zhang, C.; Li, F.; Chen, J.; Zhou, Q. Photo-reductive defluorination of perfluorooctanoic acid in water. Water Res. 2010, 44, 2939-2947. [CrossRef] [PubMed]

132. Giri, R.R.; Ozaki, H.; Okada, T.; Taniguchi, S.; Takanami, R. Factors influencing UV photodecomposition of perfluorooctanoic acid in water. Chem. Eng. J. 2012, 180, 197-203. [CrossRef]

133. Chen, J.; Zhang, P.; Liu, J. Photodegradation of perfluorooctanoic acid by $185 \mathrm{~nm}$ vacuum ultraviolet light. J. Environ. Sci. 2007, 19, 387-390. [CrossRef]

134. Hori, H.; Yamamoto, A.; Koike, K.; Kutsuna, S.; Osaka, I.; Arakawa, R. Photochemical decomposition of environmentally persistent short-chain perfluorocarboxylic acids in water mediated by iron(II)/(III) redox reactions. Chemosphere 2007, 68, 572-578. [CrossRef] 
135. Chen, Z.; Teng, Y.; Mi, N.; Jin, X.; Yang, D.; Wang, C.; Wu, B.; Ren, H.; Zeng, G.; Gu, C. Highly Efficient Hydrated Electron Utilization and Reductive Destruction of Perfluoroalkyl Substances Induced by Intermolecular Interaction. Environ. Sci. Technol. 2021, 55, 3996-4006. [CrossRef]

136. Javed, H.; Lyu, C.; Sun, R.; Zhang, D.; Alvarez, P.J.J. Discerning the inefficacy of hydroxyl radicals during perfluorooctanoic acid degradation. Chemosphere 2020, 247, 125883. [CrossRef]

137. Zhang, Z.; Chen, J.-J.; Lyu, X.-J.; Yin, H.; Sheng, G.-P. Complete mineralization of perfluorooctanoic acid (PFOA) by $\gamma$-irradiation in aqueous solution. Sci. Rep. 2014, 4, 7418. [CrossRef]

138. Hori, H.; Yamamoto, A.; Hayakawa, E.; Taniyasu, S.; Yamashita, N.; Kutsuna, S.; Kiatagawa, H.; Arakawa, R. Efficient Decomposition of Environmentally Persistent Perfluorocarboxylic Acids by Use of Persulfate as a Photochemical Oxidant. Environ. Sci. Technol. 2005, 39, 2383-2388. [CrossRef]

139. Chen, J.; Zhang, P. Photodegradation of perfluorooctanoic acid in water under irradiation of $254 \mathrm{~nm}$ and $185 \mathrm{~nm}$ light by use of persulfate. Water Sci. Technol. 2006, 54, 317-325. [CrossRef]

140. Liang, C.; Bruell, C.J.; Marley, M.C.; Sperry, K.L. Persulfate oxidation for in situ remediation of TCE. I. Activated by ferrous ion with and without a persulfate-thiosulfate redox couple. Chemosphere 2004, 55, 1213-1223. [CrossRef]

141. Tran, T.; Abrell, L.; Brusseau, M.L.; Chorover, J. Iron-activated persulfate oxidation degrades aqueous Perfluorooctanoic acid (PFOA) at ambient temperature. Chemosphere 2021, 281, 130824. [CrossRef]

142. Yang, L.; He, L.; Xue, J.; Ma, Y.; Xie, Z.; Wu, L.; Huang, M.; Zhang, Z. Persulfate-based degradation of perfluorooctanoic acid (PFOA) and perfluorooctane sulfonate (PFOS) in aqueous solution: Review on influences, mechanisms and prospective. J. Hazard. Mater. 2020, 393, 122405. [CrossRef]

143. Wu, D.; Li, X.; Tang, Y.; Lu, P.; Chen, W.; Xu, X.; Li, L. Mechanism insight of PFOA degradation by ZnO assisted-photocatalytic ozonation: Efficiency and intermediates. Chemosphere 2017, 180, 247-252. [CrossRef]

144. Malato, S.; Fernández-Ibáñez, P.; Maldonado, M.I.; Blanco, J.; Gernjak, W. Decontamination and disinfection of water by solar photocatalysis: Recent overview and trends. Catal. Today 2009, 147, 1-59. [CrossRef]

145. National Association of Clean Water Agencies (NACWA). Available online: https:/ /www.nacwa.org/ (accessed on 22 January 2021).

146. Whitby, P.; Yu, R.; Mackey, E. Consider the Hidden Costs of PFAS Treatment. Opflow 2021, 47, 10-15. [CrossRef]

147. Olatunde, O.C.; Kuvarega, A.T.; Onwudiwe, D.C. Photo enhanced degradation of polyfluoroalkyl and perfluoroalkyl substances. Heliyon 2020, 6, e05614. [CrossRef] [PubMed] 